\title{
A review of applications of fuzzy sets to safety and reliability engineering
}

\author{
Sohag Kabir*, Yiannis Papadopoulos \\ School of Engineering and Computer Science, University of Hull, Hull, HU6 7RX, UK
}

\begin{abstract}
Safety and reliability are rigorously assessed during the design of dependable systems. Probabilistic risk assessment (PRA) processes are comprehensive, structured and logical methods widely used for this purpose. PRA approaches include, but not limited to Fault Tree Analysis (FTA), Failure Mode and Effects Analysis (FMEA), and Event Tree Analysis (ETA). In conventional PRA, failure data about components is required for the purposes of quantitative analysis. In practice, it is not always possible to fully obtain this data due to unavailability of primary observations and consequent scarcity of statistical data about the failure of components. To handle such situations, fuzzy set theory has been successfully used in novel PRA approaches for safety and reliability evaluation under conditions of uncertainty. This paper presents a review of fuzzy set theory based methodologies applied to safety and reliability engineering, which include fuzzy FTA, fuzzy FMEA, fuzzy ETA, fuzzy Bayesian networks, fuzzy Markov chains, and fuzzy Petri nets. Firstly, we describe relevant fundamentals of fuzzy set theory and then we review applications of fuzzy set theory to system safety and reliability analysis. The review shows the context in which each technique may be more appropriate and highlights the overall potential usefulness of fuzzy set theory in addressing uncertainty in safety and reliability engineering.
\end{abstract}

\section{Introduction}

Safety critical systems are extensively used in many industries, including the aerospace, automotive, medical, and energy sectors. Systems that fall into this category range from airbags in cars to propulsion systems on spacecraft; however, they all share a common property - their failure has the potential to cause catastrophic effects on human life as well as the environment. For this reason, it is expected that safety critical systems possess a high level of safety and reliability. While safety is the avoidance of harm to people and the environment, reliability is the ability to perform the intended function uninterrupted by a failure, which is often a precondition for safety. Both properties are crucial, and as systems become more complex, their prediction via analysis plays a vital role in the successful design and development of the system; at the same time, with increasing complexity analyses become increasingly difficult.

Different probabilistic risk assessment (PRA) methods have been used to evaluate system safety and reliability. Fault tree analysis (FTA) is one of the most widely used PRA approaches to estimate system safety and reliability. In fault trees, the logical connections between faults and their causes are represented graphically. FTA is deductive in nature, meaning that the analysis starts with a top event (a system failure) and works backwards from the top of the tree towards the leaves of the tree to determine the root causes of the top event. The results of the analysis show how different component failures or certain environmental conditions can combine together to cause the system failure.

After construction of a fault tree, the analyses are carried out at two levels: a qualitative level and a quantitative level. Qualitative analysis is usually performed by reducing fault trees to minimal cut sets (MCSs), which are a disjoint sum of products consisting of the smallest combinations of basic events that are necessary and sufficient to cause a hazardous situation, e.g., a system failure. In quantitative analysis, the probability of the occurrence of a system failure and other quantitative reliability indexes such as importance measures is mathematically calculated, given the failure rate or probability of individual system component. The results of quantitative analysis give analysts an indication about system reliability and also help to determine which components or parts of the system are more critical, so analysts can put more emphasis on the critical components or parts by taking necessary steps, e.g., including redundant components in the system model.

\footnotetext{
*Corresponding author. Email: s.kabir@hull.ac.uk
} 
In addition to the FTA, Failure Mode and Effects Analysis (FMEA), Event Tree Analysis (ETA), Markov chains, Bayesian networks, and Petri nets are some of the other approaches that are used for safety and reliability evaluation of systems. In all the PRA approaches, the system failure probability is evaluated as a function of the failure probability of the system components (e.g. the basic events). Therefore, the applicability of these analysis methods for evaluating system safety and reliability is largely dependent on the availability of the components' lifetime data. Any uncertainties raised in the components failure probability will consequently propagate it to the results. On the other hand, unavailability of failure data would introduce degrees of uncertainty into the analysis results.

In the classical forms of the PRA approaches, failure rates, failure probabilities or other numerical data related to the failure behaviour of system components are usually considered known. But in large and complex systems, not all such data is known due to limited observation and scarcity of statistical data [127, 209]. This situation is especially relevant in the early design stages, when the requirements and specifications of system components are incomplete, and in the case of new and complex software components. The failure probability of a relatively new component with insufficient historical failure data could, in theory, be estimated based on expert judgment or experience from similar components. Consequently, system safety and reliability could be evaluated based on generic statistical data, which may be taken from existing reliability databases. However, the use of generic data will add further uncertainty and imprecision to the results of the analysis.

By allowing imprecision and approximate analysis, fuzzy logic enables incorporating uncertainty in the analysis. Fuzzy set theory was firstly used in FTA for system reliability analysis in 1983 [216]. Since then, a number of researchers have developed different fuzzy set theory based FTA methodologies for system safety and reliability analysis, and many researchers have used these methodologies in a variety of application areas such as nuclear power plants, the process industries etc. Fuzzy set theory has also been applied in conjunction with dynamic extensions of the fault trees $[232,96]$. The application of fuzzy set theory in safety and reliability engineering has been extended to FMEA, ETA, Bayesian networks, and Petri nets.

The last two decades have seen the development of new techniques for model-based safety and reliability analysis, including HiP-HOPS [168,169], ALTARICA [9], and XSAP [17, 23] which in various ways automate the production of analysis artefacts like fault trees and FMEAs. The issue of both aleatoric and epistemic uncertainties have not been addressed adequately in these new techniques. The aleatoric uncertainty is due to randomness of a physical system or natural variation, whereas the epistemic uncertainty is because of ambiguity, incompleteness, and lack of knowledge. We hope that this paper will provide some of the background to help stimulate research in addressing this issue.

This paper reviews different concepts of using fuzzy set theory in systems safety and reliability engineering, to reflect the current status of the fuzzy set theory based PRA methodologies, and their applications. The paper is organised as follows: Section 2 describes the fundamentals of fuzzy set theory. Fuzzy FTA, FMEA and ETA are reviewed in sections 3, 4 and 5 respectively. Fuzzy Bayesian networks, Markov chains, and Petri nets methodologies are reviewed in section 6. A discussion and future research directions are presented in section 7. Concluding remarks are provided in section 8.

\section{Fundamentals of Fuzzy Theory}

\subsection{Fuzzy Sets and Numbers}

Fuzzy set theory was introduced by Zadeh [269] to deal with imprecise, vague or partially true information. In classical set theory, membership of an element in a set is considered to be binary, i.e., either the element belongs to a set or does not belong to a set. However, fuzzy set theory allows an element of a set to have a membership value from the interval $[0,1]$. Let $X$ be a collection of object universe and its elements are represented by $x$. A fuzzy set $A$ in $X$ can be characterised by a membership function $\mu_{\mathrm{A}}: X \rightarrow[0,1]$. The value of function $\mu_{\mathrm{A}}(x)$ represents the degree of membership of $x$ in $A$. A membership value 1 means the element is completely in set $A$ 
and 0 means the element is completely not in set $A$. On the other hand, values between 0 and 1 represent the partial membership, where the higher the value the stronger the degree of membership is.

A fuzzy number could be defined in different forms depending on the nature of the problem in hand. In [145], the authors have mentioned that any shape of membership function could be applied to reliability analysis of engineering systems. Among different shape of membership functions, the triangular and the trapezoidal shapes are widely used in reliability engineering to represent fuzzy failure rates or probabilities of system components.

Let $x, a_{1}, a_{2}, a_{3}, a_{4} \in \mathbb{R}$. A triangular fuzzy number $A$ could be defined by the membership function $\mu_{\mathrm{A}}$ as follows:

$$
\mu_{\mathrm{A}}(x)=\left\{\begin{array}{lr}
\frac{x-a_{1}}{a_{2}-a_{1}}, & \text { for } a_{1}<x<a_{2}, \\
\frac{a_{3}-x}{a_{3}-a_{2}}, & \text { for } a_{2} \leq x<a_{3}, \\
0, & \text { otherwise. }
\end{array}\right.
$$

In the triangular fuzzy number $A=\left(a_{1}, a_{2}, a_{3}\right)$, the element ' $a_{2}$ ' gives the maximal degree of membership, i.e., $\mu_{\mathrm{A}}\left(a_{2}\right)=1$, meaning that $a_{2}$ is the value with the highest degree of membership. At the same time, $a_{1}$ and $a_{3}$ are the lower and upper bound of the evaluation data, respectively.

Similar to the triangular fuzzy number, the membership function of the trapezoidal fuzzy number could be written as:

$$
\mu_{\mathrm{A}}(x)=\left\{\begin{array}{lr}
\frac{x-a_{1}}{a_{2}-a_{1}}, & \text { for } a_{1}<x<a_{2}, \\
1, & \text { for } a_{2} \leq x \leq a_{3}, \\
\frac{a_{4}-x}{a_{4}-a_{3}}, & \text { for } a_{3}<x<a_{4}, \\
0, & \text { otherwise. }
\end{array}\right.
$$

Arithmetic operations on fuzzy numbers are performed following the rules of fuzzy set theory and the extension principle [270-272, 289]. Shu, Cheng and Chang [206], Bowles and Pelaez [22], Liang and Wang [127], and Misra and Weber [154] have described different arithmetic operations on fuzzy numbers based on the extension principle.

\subsection{Computing with Words, Failure Possibility and Probability}

Computing with words $(\mathrm{CW})$ is used for computing and reasoning using words and propositions from natural language instead of numbers. The concept of CW was firstly presented in [275], where the concept of linguistic variables [270-272] and granulation were introduced [276]. The conceptual structure of CW can be found in [277]. Herrera et al. [80] have reviewed the developments of CW in decision making applications. Zadeh [270272], Trillas [221] and Mendel [148] have provided a detailed description of the tight relationship between fuzzy sets and CW and how CW can be used for computation where the data is in the form of perceptions. Mendel $[149,150]$ studied the concept of perceptual computing framework as an architecture for computing with words. Another concept, retranslation process in $\mathrm{CW}$, dealing with the issue of describing fuzzy sets in natural language (linguistic terms) has been studied in [146, 251]. Over the years, several new approaches have been proposed for CW. For instance, Lawry [112-114] presented both a novel framework for linguistic modelling and an alternative method to $\mathrm{CW}$ using the concept of mass assignment theory [13]. These approaches avoided some of the issues related to the use of the extension principle in Zadeh's CW method. Moreover, Ying [265] used fuzzy automata to propose a formal method for CW and Rubin [192] defined CW as a symbolic generalisation of fuzzy logic.

The concept of a linguistic variable plays an important role in dealing with situations which are too complex or vague in nature, i.e., very difficult to describe using conventional quantitative expressions. The values of 
linguistic variables are words or sentences in natural languages. The detail description of the steps, including how the membership functions for the linguistic terms are constructed from available data, required for solving decision-making problem with linguistic information is out of scope of the paper. However, interested readers can find more information and some approaches in [40, 41, 80, 81, 112, 146, 148, 150, 225, 226, 251]. More information about fuzzy quantifiers such their interpretations, ways of reasoning with them, and their applications can be found in $[131,132]$. Lawry $[113,115,116]$ proposed an alternative framework known as label semantics for linguistic modelling based on a random set model of the measure appropriateness of a label. Labels (linguistic terms) for values are chosen from a fixed finite set of terms. Appropriateness degrees are evaluated as the likelihood that a particular word is deemed appropriate as a label for a certain value. Further research on label semantics can be found in $[117,121,217]$.

In reliability engineering applications, we may treat the "failure possibility of component" using fuzzy quantifiers [278] such as: very low, low, fairly low, medium, fairly high, high, and very high. The graphical representation of these linguistic values is shown in Fig. 1.

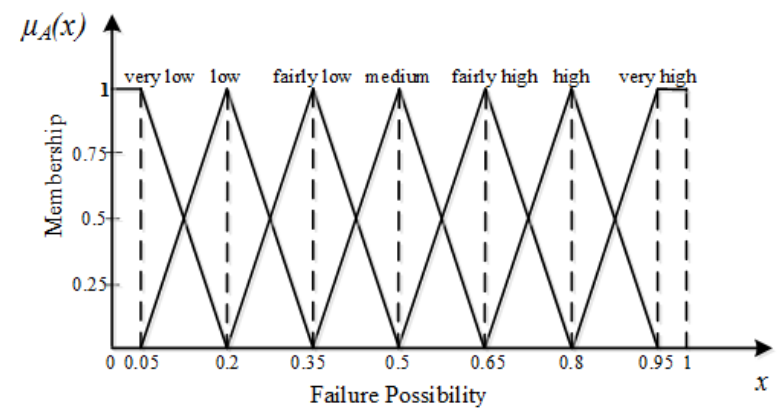

Fig. 1. Fuzzy numbers representing linguistic variables [90]

The membership functions of these linguistic variables in triangular forms are as follows:

$$
\begin{aligned}
& \mu_{\text {very low }}(x)=\left\{\begin{array}{lr}
1, & \text { for } 0 \leq x \leq 0.05, \\
\frac{0.2-x}{0.15}, & \text { for } 0.05<x<0.2, \\
0, & \text { for } x \geq 0.2 .
\end{array}\right. \\
& \mu_{\mathrm{low}}(x)=\left\{\begin{array}{lr}
\frac{x-0.05}{0.15}, & \text { for } 0.05<x \leq 0.2 \\
\frac{0.35-x}{0.15}, & \text { for } 0.2<x<0.35 \\
0, & \text { otherwise }
\end{array}\right. \\
& \mu_{\text {fairly low }}(x)=\left\{\begin{array}{lr}
\frac{x-0.2}{0.15}, & \text { for } 0.2<x \leq 0.35 \\
\frac{0.5-x}{0.15}, & \text { for } 0.35<x<0.5 \\
0, & \text { otherwise }
\end{array}\right. \\
& \mu_{\text {medium }}(x)=\left\{\begin{array}{lr}
\frac{x-0.35}{0.15}, & \text { for } 0.35<x \leq 0.5 \\
\frac{0.65-x}{0.15}, & \text { for } 0.5<x<0.65 \\
0, & \text { otherwise }
\end{array}\right.
\end{aligned}
$$




$$
\begin{gathered}
\mu_{\text {fairly high }}(x)=\left\{\begin{array}{lr}
\frac{x-0.5}{0.15}, & \text { for } 0.5<x \leq 0.65, \\
\frac{0.8-x}{0.15}, & \text { for } 0.65<x<0.8, \\
0, & \text { otherwise. }
\end{array}\right. \\
\mu_{\text {high }}(x)=\left\{\begin{array}{cc}
\frac{x-0.65}{0.15}, & \text { for } 0.65<x \leq 0.8, \\
\frac{0.95-x}{0.15}, & \text { for } 0.8<x<0.95, \\
0, & \text { otherwise. }
\end{array}\right. \\
\mu_{\text {very high }}(x)=\left\{\begin{array}{cr}
\frac{x-0.8}{0.15}, & \text { for } 0.95 \leq x \leq 1, \\
0, & 0.8<x<0.95,
\end{array}\right.
\end{gathered}
$$

Users of linguistic variables would have to define the failure possibility distribution (values for membership functions) for different variables based on the nature of the system they want to analyse. However, the results may vary from user to user due to the subjective nature of this task. In [189, 190], Ross proposed six different methods - intuition, inductive reasoning, inference, rank ordering, genetic algorithm, and neural networks to assign value to a fuzzy variable. Purba $[175,176]$ used the inductive reasoning approach to assign fuzzy failure possibilities in linguistic terms. Both hardware failure rates and human error could be represented by using linguistic variables [129].

Although, both possibilities and probabilities are defined on the interval $[0,1]$ and they provide a measure for uncertainty, they are fairly different. The difference between these two concepts was explained in [101,273]. According to Zadeh [273], the probability is associated with a degree of belief, frequency or likelihood whereas possibility is related to human perception of the degree of feasibility. Possibility of failure may impose an upper bound on the probability of failure, i.e., the degree of possibility of an event occurring is greater than or equal to the degree of probability that event occurring. That means that if an event is highly probable then it must also be highly possible and if an event is not possible, then it is also not probable, however, high possibility of an event does not guarantee the high probability of the event. Both failure possibility and failure probability concepts have been used for representing failure data of system components in reliability engineering. For example, the failure possibility of system components in fuzzy forms has been used in [101, 209, 228], whereas failure probability in fuzzy forms has been used in $[52,180,213]$. The ways of defining the probability of an event in fuzzy sets are available in $[22,274]$. The possibility of an event could be converted to the probability of the event by following the process described in [160]. If FP and FPS represent failure probability and possibility of an event respectively, then according to [160], FP can be derived from FPS as:

$F P= \begin{cases}\frac{1}{10^{K}}, & \text { if } F P S \neq 0 \\ 0, & \text { if } F P S=0\end{cases}$

and

$K=\left(\frac{1-F P S}{F P S}\right)^{1 / 3} \times 2.301$

As it is possible to transform possibility into probability and vice versa, possibility and probability are often considered together while performing safety and reliability analysis under limited information. If probability is used for the analysis of a system with many failure modes, then the results can be more conservative than that of the results obtained use possibility. For this reason, if little information is known about failure data, the conservative possibilistic model is preferred over the conservative probabilistic model, which is harder to determine. Moreover, when the analysts' task is to maximize safety or reliability under a cost constraint, the possibilistic model can be less sensitive to errors than its probabilistic counterpart [3]. 


\subsection{Approximation of Fuzzy failure data for events}

The triangular and trapezoidal forms are widely used in reliability engineering for the fuzzy representation of failure data of components. Once the shape is decided, it is necessary to obtain/generate the data in the specified shape. There exist different methods such as a percentage of lower and upper bounds, expert knowledge elicitation, and $3 \sigma$ expression [141].

Consider a triangular fuzzy set as $\tilde{A}=\left\{x_{1}, x_{2}, x_{3}\right\}$ with $\mu_{\tilde{A}}\left(x_{2}\right)=1, \mu_{\tilde{A}}\left(x_{1}\right)=\mu_{\tilde{A}}\left(x_{3}\right)=0$, and $\left[x_{1}, x_{3}\right]$ are lower bound and upper bound of the triangular set. If specific statistical data are not available about the failure probability of a component, these values may be obtained from the point median value and the error factor of the failure probability [127]. A point median value can be considered as a crisp approximation of the failure probability of a component, which is used as a guide value in the fuzzy data generation process. Note that this value is subjective and can be calculated from the failure data of similar components by consulting reliability databases such as OREDA [161] or can be provided directly by an expert. For instance, consider that for a component $C$ we find failure data of five similar components in a database and the data are sorted in order as $f 1$, $f 2, f 3, f 4, f 5$. Therefore, for this example, the point median value is $f 3$. On the other hand, if there are six data points $f 1, f 2, f 3, f 4, f 5, f 6$, then the median value is $(\mathrm{f} 3+\mathrm{f} 4) / 2$. Error factor is the percentage level of error allowed in the failure probability of the component. The system analyst decides the error factor and the value can vary widely depending on the application area and the criticality of the system under study.

According to [69, 213], the value of $x_{1}, x_{2}$, and $x_{3}$ can be defined as:

$$
\begin{gathered}
x_{1}=\frac{q_{p}}{E F} \\
x_{2}=q_{p} \\
x_{3}=q_{p} \times E F
\end{gathered}
$$

where $q_{p}$ is the point median value of the failure probability and EF is the error factor. Some researchers also defined these values as: $\tilde{A}=\left\{x_{1}, x_{2}, x_{3}\right\}=\left\{q_{p}-E F \times q_{p}, q_{p}, q_{p}+E F \times q_{p}\right\}$.

When statistical data even for similar components is too scarce, expert knowledge elicitation is used [206, 259]. The authors in [267] collected experts' knowledge through several interviews using a questionnaire to approximate the failure possibility of events. In the expert knowledge elicitation process, a set of experts, who are familiar with the system under consideration, knowledgeable about the operating environment of the system, and have considerable training and knowledge of the system operation, are provided with a set of events so that they can give their opinion about the failure probability of the events.

As the experts are human beings, their opinions could vary widely due to their level of expertise, experience and their background. In order to achieve an agreement among the contrasting observations of the experts, it is necessary to combine their opinions. There are many general approaches such as mean, median, min and max operators [42] available to aggregate fuzzy numbers (opinions). The simplest way of aggregating fuzzy numbers is to take an arithmetic average of different numbers.

Consider, for the failure probability of an event $i$, different experts $j(j=1,2, \ldots, n)$ are asked to provide their opinions and their opinions are in the form of triangular fuzzy number: $\tilde{A}_{i j}=\left\{x_{i j}, y_{i j}, z_{i j}\right\}$. These opinions can be aggregated by taking their average as:

$$
\tilde{A}=\frac{\tilde{A}_{i 1} \oplus \tilde{A}_{i 2} \oplus \tilde{A}_{i 3} \oplus \ldots \oplus \tilde{A}_{i n-1} \oplus \tilde{A}_{i n}}{n}
$$

where $\tilde{A}$ is the average of the fuzzy opinions and $\bigoplus$ is arithmetic summation operator for fuzzy numbers. 
This approach gives equal weight to all the experts regardless of their knowledge, experience and expertise. In practice, experts with better experience and knowledge are given higher weight. In order to take the weightings of the experts into account, it is possible to take a weighted average of the opinions.

To illustrate how expert opinions can be used to obtain failure data as triangular fuzzy numbers, consider the data in Table 1 as different scoring criteria to take into account the experience, knowledge, and expertise into account in the aggregation process.

Table 1. Weighting scores of experts [184]

\begin{tabular}{ccc}
\hline Constitution & Classification & Score \\
\hline & Professor, GM/DGM, Chief Engineer, Technical & 5 \\
& Director & 5 \\
Professional position & Assistant professor, Technology Manager, Factory & 4 \\
& inspector & 3 \\
& Engineer, Supervisors & 2 \\
& Foreman, Technician, Graduate apprentice & 1 \\
& Operator & 5 \\
Experience (in years) & $\geq 20$ & 4 \\
& 15 to 19 & 3 \\
& 10 to 14 & 2 \\
Education/technical & 5 to 9 & 1 \\
qualification & $<5$ & 5 \\
& PhD or MTech & 4 \\
& MSc or BTech & 3 \\
& Diploma or BSc & 2 \\
& ITI & 1 \\
\hline
\end{tabular}

For instance, $M$ experts are employed to provide their opinion regarding failure probability of a component and the experts provide their opinion in linguistic terms such as VL (very low), L (Low), H (high), and VH (very high) etc. The corresponding triangular fuzzy number of expert $i$ 's opinion can be written as: $\tilde{A}_{i}=$ $\left(a_{i 1}, a_{i 2}, a_{i 3}\right)$. Note that the correspondence between linguistic terms and fuzzy numbers can be obtained by the methods mentioned in section 2.2. Once all the experts provided their opinion, similarity aggregation method (SAM) $[83,184]$ is used to aggregate their opinions. As part of SAM, a similarity matrix (S) is formed as follows:

$$
S=\left[\begin{array}{cccc}
1 & S_{12} & \ldots & S_{1 M} \\
S_{21} & 1 & \ldots & S_{2 M} \\
\vdots & \vdots & \vdots & \vdots \\
S_{M 1} & S_{M 2} & \ldots & 1
\end{array}\right]
$$

Where $S_{i j}$ represents the similarity between the opinions of expert $i$ and $j$, and it can be calculated as in [184, 242]:

$$
S_{i j}=1-\frac{\sum_{k=1}^{3}\left|a_{i k}-a_{j k}\right|}{3}
$$

The average agreement $\left(A A\left(E x_{i}\right)\right)$ for each of the experts is calculated as:

$$
A A\left(E x_{i}\right)=\frac{\substack{\sum_{i \neq j}^{M} S_{i j} \\ M-1}}{M-1}
$$

The relative agreement degree $\left(R A D\left(E x_{i}\right)\right)$ is calculate as:

$$
R A D\left(E x_{i}\right)=\frac{A A\left(E x_{i}\right)}{\sum_{j=1}^{M} A A\left(E x_{j}\right)}
$$


Using the weighting criteria from Table 1, the weighting factor of each expert is calculated as:

$$
W F\left(E x_{i}\right)=\frac{W S\left(E x_{i}\right)}{\sum_{j=1}^{M} W S\left(E x_{j}\right)}
$$

Where $W F\left(E x_{i}\right)$ is the weighting factor of expert $E x_{i}$ and $W S\left(E x_{i}\right)$ is the total weight scored by expert $E x_{i}$.

Weighting factor and relative agreement degrees are then used to calculate the consensus coefficient $\left(C C\left(E x_{i}\right)\right)$ as follows:

$$
C C\left(E x_{i}\right)=\beta \cdot W F\left(E x_{i}\right)+(1-\beta) \cdot R A D\left(E x_{i}\right)
$$

Where $\beta(0 \leq \beta \leq 1)$ is a relaxation factor, which can be determined by the analysts, and represents the importance of $W F\left(E x_{i}\right)$ over $R A D\left(E x_{i}\right)$. If $\beta$ is set to 0 then no importance will be given to the weight of experts. Finally, the aggregated opinion of the experts is determined as:

$$
\tilde{A}=\sum_{i=1}^{M}\left(C C\left(E x_{i}\right) \times \tilde{A}_{i}\right)
$$

Where $\tilde{A}$ is the aggregated opinion in triangular form.

Note that the above example illustrates only the use of a particular aggregation method (i.e., SAM). There are many other alternative aggregation procedures available that can be used for the above purpose. A survey on such approaches is available in [230]. Examples of such approaches include, but are not limited to: the weighted minimum and the weighted maximum [49, 252], ordered weighted averaging operators [253], symmetric sum [207], Choquet \& Sugeno discrete fuzzy integrals [36, 211], t-norm and t-conorm [103, 196, 197], consistency aggregation method (CAM) [139, 242], iterative optimal aggregation method [118], and coordination index and similarity based aggregation [223].

\subsection{Defuzzification Techniques}

As fuzzy numbers are used for uncertainty quantification process in system safety and reliability engineering, the results obtained are also fuzzy numbers. Defuzzification is a process of converting fuzzy numbers into crisp values. A number of approaches, such as: the weighted average approach, the mean max membership approach, the centre of area approach, the mean of maxima approach, the centre of maxima approach, and the centroid approach are available for defuzzification process [189, 237]. As mentioned in [84], no single defuzzification technique is suitable for all applications. The "centre of area" method is one of the widely used methods for the defuzzification of fuzzy numbers in reliability engineering applications. According to this method, a triangular fuzzy number $\tilde{A}=\left\{a_{1}, b_{1}, c_{1}\right\}$ can be defuzzified as:

$$
X=\frac{\int x \mu_{\tilde{A}}(x) d x}{\int \mu_{\tilde{A}}(x) d x}=\frac{\int_{a_{1}}^{b_{1}} \frac{x-a_{1}}{b_{1}-a_{1}} x d x+\int_{b_{1}}^{c_{1}} \frac{c_{1-x}}{c_{1}-b_{1}} x d x}{\int_{a_{1}}^{b_{1}} \frac{x-a_{1}}{b_{1}-a_{1}} d x+\int_{b_{1}}^{c_{1}} \frac{c_{1-x}}{c_{1}-b_{1}} d x}=\frac{1}{3}\left(a_{1}+b_{1}+c_{1}\right)
$$

The centroid method has been used for defuzzification in $[163,165]$ for building constructions application and in [75] for conveyor system. Recently, Purba [176] has proposed an area defuzzification technique to apply it to nuclear power plant. Using this approach a triangular fuzzy number $\tilde{A}=\left\{a_{1}, b_{1}, c_{1}\right\}$ can be defuzzified as:

$$
X=\frac{1}{18}\left(4 a_{1}+b_{1}+c_{1}\right)
$$

A defuzzified value could represent either failure possibility or failure probability. As mentioned in section 2.2, failure possibility can be converted to failure probability using equation (4). It is important to note that the use 
of fuzzy data would not create any accuracy where none previously existed. The main advantage of starting reliability analysis using fuzzy data is that it allows considering a broad range of values where precise data is not available. At the end of the analysis, in many cases, the defuzzification techniques may be used to get a crisp value. This is usually done when the reliability requirement for a system is given as a crisp value, because analysts have to compare their results with the requirement to check if the requirement has been met by a particular system design. On the other hand, if the reliability requirement is given as a range of values then there is no need for defuzzification.

\section{Fuzzy Fault Tree Analysis}

The pioneering work on the application of fuzzy set theory in FTA was done by Tanaka et al. [216]. In this work, failure probabilities of the basic events of a fault tree were represented as fuzzy numbers and these values were used to determine the probability of the top event of fault tree in the fuzzy form. After this work, Furuta and Shiraishi [59] have proposed an approach to include importance measures in the fuzzy FTA. Based on [216], further research has been performed in [127, 154]. Further work on fuzzy FTA can be found in [26, 27, 153, 162, 166, 195, 213, 291]. Fuzzy set theory has also been applied to dynamic extensions of the fault trees such as in [96, 124, 232, 256]. A generic overview of the fuzzy fault tree analysis is shown in Fig. 2.

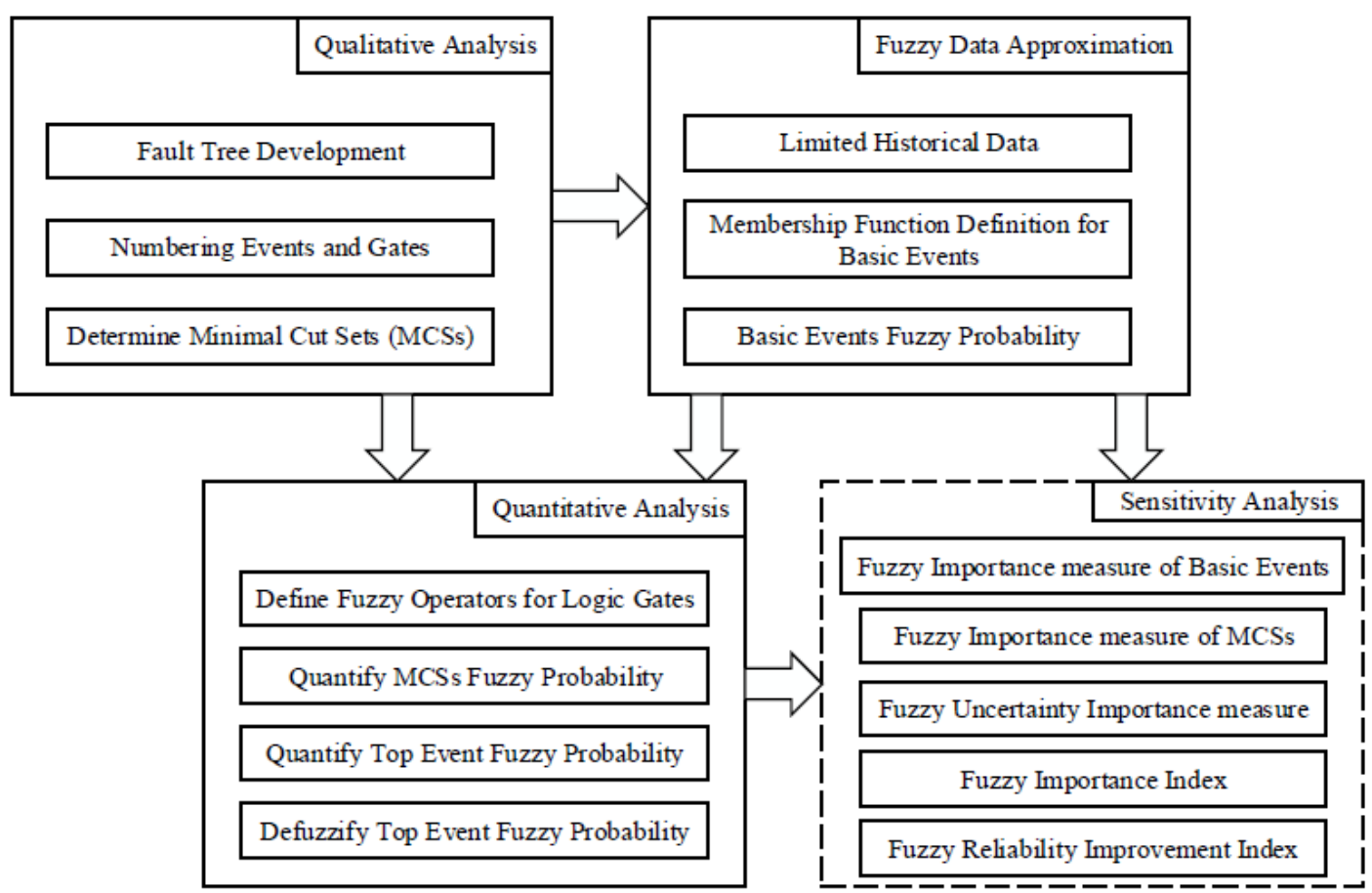

Fig. 2. A graphical overview of the fuzzy fault free analysis

The figure shows four phases in the FFTA of a system. In the qualitative analysis phase, the fault trees are developed, fault tree gates and events are numbered and finally minimal cut sets are determined. There are many tools available to create fault trees and a list of these tools is available in [91]. The outcomes of the qualitative analysis (basic events) feed into the fuzzy data approximation and quantitative analysis phases. Quantitative analysis uses cutsets and fuzzy probabilities for basic events derived as explained in section 2. Although mathematical formulae are available to quantify AND and OR operators that link events in cutsets, these are only suitable for crisp values. For this reason, it is necessary to define fuzzy operators for logic gates. 


\section{Fuzzy Operators for Logic Gates}

AND gate fuzzy operator:

The output of the AND gate becomes true when all the inputs become true. The probability of an AND gate with $N$ input events can be determined as [79]:

$$
\operatorname{Pr}\left\{E_{1} \cdot E_{2} \cdot E_{3} \ldots . E_{N-1} \cdot E_{N}\right\}(t)=\prod_{i=1}^{N} \operatorname{Pr}\left\{E_{i}\right\}(t)
$$

Where $\operatorname{Pr}\left\{E_{i}\right\}(t)$ is the probability of event $E_{i}$ at time $t$. If the failure rate of a system component corresponding to an event $E_{i}$ is exponentially distributed and represented as $\lambda$, then $\operatorname{Pr}\left\{E_{i}\right\}(t)$ can be calculated as: $\operatorname{Pr}\left\{E_{i}\right\}(t)=$ $1-e^{-\lambda t}$. Now, if the fuzzy probability of the event $E_{i}$ is represented by a triangular fuzzy number as $P_{i}(t)=$ $\left\{a_{i}(t), b_{i}(t), c_{i}(t)\right\}$, then the fuzzy operator for the AND gate is defined as:

$$
P_{F A N D}=A N D_{F}\left\{P_{1}(t), P_{2}(t), \ldots, P_{N}(t)\right\}=\prod_{i=1}^{N} P_{i}(t)=\left\{\prod_{i=1}^{N} a_{i}(t), \prod_{i=1}^{N} b_{i}(t), \prod_{i=1}^{N} c_{i}(t)\right\}
$$

OR gate fuzzy operator:

The probability of an OR gate with $N$ input events can be approximated as [51]:

$$
\operatorname{Pr}\left\{E_{1}+E_{2}+E_{3}+\ldots+E_{N-1}+E_{N}\right\}(t)=1-\prod_{i=1}^{N}\left(1-\operatorname{Pr}\left\{E_{i}\right\}(t)\right)
$$

Where $\operatorname{Pr}\left\{E_{i}\right\}(t)$ is the probability of the occurrence of the event $E_{i}$ at time $t$. In the context of FTA, as the top event of a fault tree is usually represented as disjunction of minimal cut sets, the outcome of the above equation would represent the failure probability of a system at time $t$, i.e., unreliability of the system after a specified time $t$.

Based on the above formula, the fuzzy operator for the OR gate is defined as:

$$
\begin{aligned}
P_{F O R}=O R_{F}\left\{P_{1}(t)\right. & \left., P_{2}(t), \ldots, P_{N}(t)\right\}=1-\prod_{i=1}^{N}\left(1-P_{i}(t)\right) \\
= & \left\{1-\prod_{i=1}^{N}\left(1-a_{i}(t)\right), 1-\prod_{i=1}^{N}\left(1-b_{i}(t)\right), 1-\prod_{i=1}^{N}\left(1-c_{i}(t)\right)\right\}
\end{aligned}
$$

Authors in $[92,96,268]$ have also defined fuzzy operators for dynamic and temporal fault tree gates such as functional dependency gate (FDEP), Priority-AND (PAND) gate and Priority-OR(POR) gate. Interested readers are referred to these articles for further details of these gates and their fuzzy operators. Once the fuzzy operators are defined, these operators and the fuzzy data are used to calculate the fuzzy probability of the minimal cut sets and the top event. Top event fuzzy probability is finally defuzzified to obtain a crisp probability.

For illustration, consider the simple fault tree in Fig. 3. The top event of this fault tree can be logically expressed as:

$$
\text { Top event }=\mathrm{A} 1+\mathrm{A} 2=\mathrm{X} 1 . \mathrm{X} 2+\mathrm{X} 3 \cdot \mathrm{X} 4
$$

where '十' and '.' represent logical OR and AND, respectively. Fuzzy failure rates and fuzzy failure probabilities of the basic events in triangular form are shown in Table 2. 


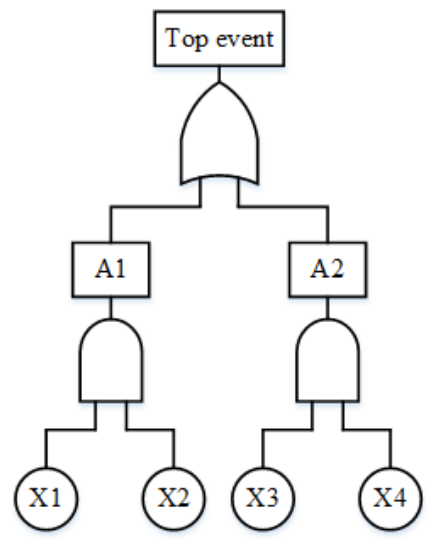

Fig. 3. Fault tree to illustrate Fuzzy FTA

Table 2. Fuzzy failure data for basic events ( $\mathrm{t}=1000$ hours)

\begin{tabular}{ccccccc}
\hline \multirow{2}{*}{ Event Id } & \multicolumn{3}{c}{ Fuzzy Failure Rates } & \multicolumn{2}{c}{ Fuzzy failure Probabilities } \\
\cline { 2 - 6 } & $\lambda_{i 1}$ & $\lambda_{i 2}$ & $\lambda_{i 3}$ & $a_{i}(t)$ & $b_{i}(t)$ & $c_{i}(t)$ \\
\hline$X_{1}$ & $1.005 \mathrm{E}-5$ & $2.020 \mathrm{E}-5$ & $3.046 \mathrm{E}-5$ & 0.01 & 0.02 & 0.03 \\
$X_{2}$ & $2.020 \mathrm{E}-5$ & $4.082 \mathrm{E}-5$ & $5.129 \mathrm{E}-5$ & 0.02 & 0.04 & 0.05 \\
$X_{3}$ & $3.046 \mathrm{E}-5$ & $5.129 \mathrm{E}-5$ & $6.188 \mathrm{E}-5$ & 0.03 & 0.05 & 0.06 \\
$X_{4}$ & $3.046 \mathrm{E}-5$ & $4.082 \mathrm{E}-5$ & $5.129 \mathrm{E}-5$ & 0.03 & 0.04 & 0.05 \\
\hline
\end{tabular}

Note that these data is only for illustrative purposes. Section 2.3 explains how such data can be obtained. Furthermore, from the existing literatures related to fuzzy fault tree analysis, interested readers can find different ways of generating fuzzy data. Using the fuzzy operators of AND gate and the data from table 2, the fuzzy probabilities of the minimal cut sets can be estimated as: $\operatorname{Pr}\{\mathrm{A} 1\}(\mathrm{t})=\{0.0002,0.0008,0.0015\}$ and $\operatorname{Pr}\{\mathrm{A} 2\}$ $(t)=\{0.0009,0.0020,0.0030\}$. Now using the fuzzy operators of the OR gate and the fuzzy probabilities of the MCSs, the fuzzy top event probability is: $\operatorname{Pr}\{$ Top event $\}=\{0.0011,0.0028,0.0045\}$. This result implies that the probability of the top event is between 0.0011 and 0.0045 , and the most probable value is 0.0028 . The fuzzy values could be defuzzified using the techniques mentioned in section 2.4. According to the centre of area method the defuzzified value of the above fuzzy number is 0.0028 .

The final phase of the FFTA is the sensitivity analysis and this phase is not always executed. For this reason, this phase is represented as dotted rectangle (see Fig. 2), meaning that this phase is optional. In this phase, fuzzy importance measures of the basic events, intermediate events, and other related indexes are calculated based on fuzzy data to determine the various contributions of the basic or intermediate events on the occurrence of the top event. In classical FTA, Fussell-Vesely and Birnbaum importance measures are used for the above purpose [233]. In fuzzy FTA, Suresh at al. [213] and Guimarees and Ebecken [69] proposed methodologies to measure the importance of basic events based on their contributions to the occurrence of the top event and also their uncertainty contribution to the uncertainty of the top event. They named the former as the fuzzy importance measure (FIM) and the latter as the fuzzy uncertainty importance measure (FUIM).

The FIM of basic event $E_{i}$ is defined as:

$$
\operatorname{FIM}\left(E_{i}\right)=E D\left[Q_{q i=1}, Q_{q i=0}\right]
$$

Where $Q_{q i=1}$ is the top event fuzzy probability with basic event $E_{i}$ fully unavailable, and $Q_{q i=0}$ is the top event fuzzy probability with basic event $E_{i}$ fully available, and $E D\left[Q_{q i=1}, Q_{q i=0}\right]$ is the Euclidean distance between $Q_{q i=1}$ and $Q_{q i=0}$. Euclidean distance between two fuzzy sets $\tilde{A}$ and $\tilde{B}$ is defined as:

$$
E D[\tilde{A}, \tilde{B}]=\sum\left(\left(a_{L}-b_{L}\right)^{2}+\left(a_{U}-b_{U}\right)^{2}\right)_{\alpha i}^{0.5}, \alpha i=1,2, \ldots, N
$$

Where $a_{L}, b_{L}$ and $a_{U}, b_{U}$ are the lower and upper values of the fuzzy set $\tilde{A}$ and $\tilde{B}$ at each $\alpha$ level, respectively. Each $\alpha$ level represents a value for $\alpha(0 \leq \alpha \leq 1)$, which is used to determine the $\alpha$-cut of the membership 
function of a fuzzy set by determining all values $x$ whose membership in that particular fuzzy set is greater than or equal to $\alpha$.

FUIM of basic event $E_{i}$ is defined as:

$$
\operatorname{FUIM}\left(E_{i}\right)=E D\left[Q, Q_{i}\right]
$$

Where $\operatorname{FUIM}\left(E_{i}\right)$ is the fuzzy uncertainty importance measure of event $E_{i} . Q$ is the top event failure probability and $Q_{i}$ is the top event failure probability considering the error factor for event $E_{i}$ as unity, i.e., the basic event's failure probability is a crisp value. FIM can help to identify the critical components of the system, thereby it can help system analysts to determine which components require more attention. On the other hand, FUIM can help to identify components that contribute most to the uncertainty, which will help in deciding the components for which more information should be collected. Different other approaches for sensitivity analysis in fuzzy FTA have also been proposed. For example, [127, 227] proposed another importance measure called fuzzy importance index (FII) while Chanda and Bhattacharjee [27] have proposed a reliability improvement index (RII). Table 3 lists papers that either proposed new approaches for sensitivity analysis and/or applied existing approaches for sensitivity analysis with fuzzy data.

Generally in FFTA, fuzzy operators are defined for different logic gates and fuzzy probability data for basic events are then used in conjunction with operators to obtain different fuzzy reliability indexes. Another way of using fuzzy set theory with FTA is known as fuzzy hybrid fault tree analysis [129, 175]. An overview of this approach is shown in Fig. 4. The qualitative analysis phase is same as the classical FFTA. The data input phase. performs all the tasks performed in the fuzzy data approximation phase of a classical FFTA, but it also defuzzifies the basic event probabilities to obtain crisp values. As crisp values are provided to the quantitative analysis phase, this phase does not need to define fuzzy operators for the logic gates. Using the classical formulas for the logic gates and the single failure probability data, the hybrid approach estimates the MCSs probability and the top event probability as single values. Unlike the classical FFTA, this approach performs the sensitivity analysis based on crisp values using the approaches developed for classical FTA.

Fuzzy FTA has been applied in a wide varieties of areas. For example, Lavasani et al. [110, 111], Yuhua and Datao [267], and Wang, Zhang, and Chen [242] have applied FFTA in process industries, Purba [176] and Purba et al. [180] have used FFTA in nuclear industries, etc. FFTA has not only been used for reliability assessment of systems, it has also been applied for fault diagnosis, e.g. in [14,31, 67, 171]. A literature review of fuzzy fault tree analysis is available in $[91,141]$ and a comprehensive list of references on developments and applications of fuzzy FTA till 2013 is available in [141]. Since 2013, some new developments and significant new applications of the FFTA have been noticed. Table 3 summarises those developments and applications of FFTA. 
Table 3. Developments and applications of FFTA since 2013

Category

New developments in fuzzy set based classical FTA

New developments in fuzzy set based Dynamic FTA

Applications

Fuzzy Sensitivity Analysis

\section{Papers}

Purba [176], Kim et al. [102], Senol and Sahin [200], Shi et al. [205], Gierczak [65],

Mhalla et al. [151], Flage et al. [56], Kumar and Singh [108], Ardeshir et al. [8], Chen et al. [32], Rajakarunakaran et al. [184], Wang et al. [240, 241, 243], Xia [249], Zhang et al. [281-283], Xu et al. [250], Purba et al. [177, 178, 180], Purba and Tjahyani [179], Sen et al. [198], Komal [105], Troger et al. [222], Nadjafi et al.[157], Verma et al. [231], Aqlan and Ali [7], Vishwakarma and Sharma [236], and Yazdi [258, 262].

Kabir et al. [92, 96], Tu et al. [224], Huang et al. [85], Duan and Zhou [47], Abdo and Flaus [1], Yuyan et al.[268], Duan and Fan [48].

Lavasani et al. [110, 111], Wang et al. [242], Senol et al. [199], Purba [176], Shi et al. [205], Hou et al. [82], Gierczak [65], Mhalla et al. [151], Lin et al. [128], Du and Li [46], Ardeshir et al. [8], Yiu et al. [266], Li et al. [123, 125], Ding et al. [43],

Chen et al. [32], Zheng et al. [285], Wang [238], Rajakarunakaran et al. [184], Aung et al. [10], Qi et al. [182], Mirza et al. [152], Lu and Wei [140], Xia [249], Xu et al. [250], Sen et al. [198], Huang et al. [85], Komal [105], Zhang et al. [281, 282], Mou et al. [156], Zhu et al. [288], Nadjafi et al.[157], Verma et al. [231], Aqlan and Ali [7], Duan and Fan [48], Yazdi [261].

Lavasani et al. [110, 111], Ramzali et al. [185], Wang et al. [242], Senol et al. [199], Shi et al. [205], Du and Li [46], Kabir et al. [96], Li et al. [125], Ding et al. [43],

Chen et al. [32], Zheng et al. [285], Rajakarunakaran et al. [184], Aung et al. [10], Qi et al. [182], Zhang et al. [283], Huang et al. [85], Komal [105], Yuyan et al.[268], Zhu et al. [288], Zhang et al. [282], Purba et al. [181] .

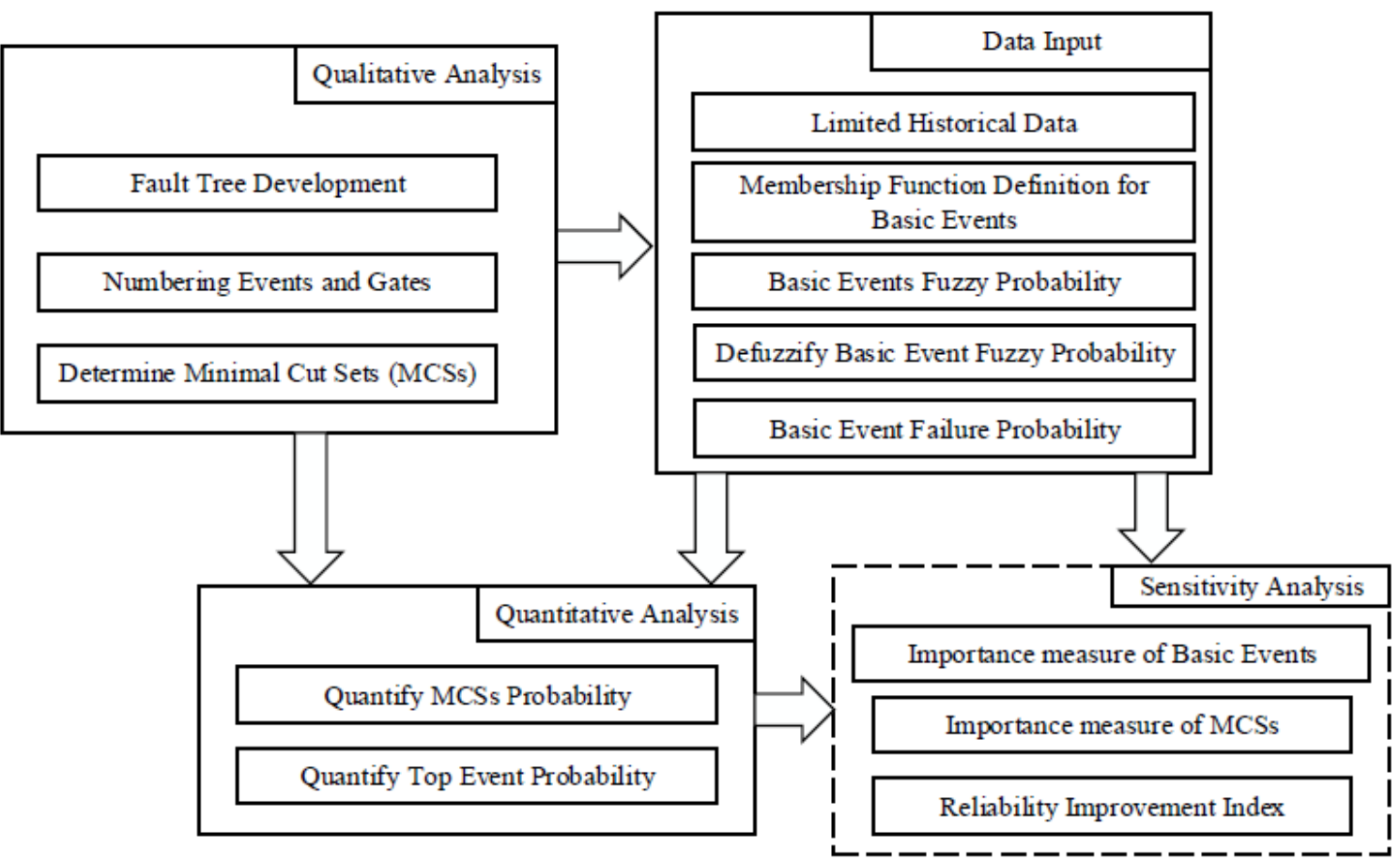

Fig. 4. A graphical overview of Fuzzy Hybrid Fault Tree Analysis 


\section{Fuzzy FMEA}

Failure Mode and Effects Analysis (FMEA) is a well-known inductive safety analysis method, which examines the potential effects of a component failure in the system operation and determines the ways of eliminating those failures to enhance system safety and reliability. The FMEA process is given in $[172,210]$. It starts with defining the system, identifying and listing all components of the system with their potential failure modes. Quantitative analysis follows by calculating a risk priority number (RPN) for each failure mode. The RPN is calculated as:

$$
R P N=O \times S \times D
$$

Where $O$ is the occurrence probability of the failure, $S$ is the severity of the failure, and $D$ is the probability of not detecting the failure. These three values are evaluated using the 10-point scale as shown in Tables 4-6. The failure modes are prioritised based on their RPN values. The higher the RPN of a failure mode, the greater the criticality of that failure mode, hence, the failure mode is given a higher priority than those having a lower RPN.

Table 4. Conventional crisp ratings for the occurrence of failure (O) [28-30, 34, 35, 57, 134, 137, 201, 239]

\begin{tabular}{lll}
\hline Rank & Probability of failure & Possible failure rates \\
\hline 10 & Extremely high & $\geq 1 / 2$ \\
9 & Very high & $1 / 3$ \\
8 & Repeated failures & $1 / 8$ \\
7 & High & $1 / 20$ \\
6 & Moderately high & $1 / 80$ \\
5 & Moderate & $1 / 400$ \\
4 & Relatively low & $1 / 2000$ \\
3 & Low & $1 / 15,000$ \\
2 & Remote & $1 / 150,000$ \\
1 & Nearly impossible & $1 / 1,500,000$ \\
\hline
\end{tabular}

Table 5. Conventional crisp ratings for severity of a failure (S) [28-30, 34, 35, 57, 134, 137, 201, 239]

\begin{tabular}{|c|c|c|}
\hline Rank & Effect & Description \\
\hline 10 & Hazardous & $\begin{array}{l}\text { Failure is hazardous, and occurs without warning. It suspends operation of the } \\
\text { system and/or involves noncompliance with government regulations }\end{array}$ \\
\hline 9 & Serious & $\begin{array}{l}\text { Serious effect, failure involves hazardous outcomes and/or noncompliance with } \\
\text { government regulations or standards }\end{array}$ \\
\hline 8 & Extreme & Very high effect and system is inoperable with loss of primary functionality \\
\hline 7 & Major & System performance is severely affected due to equipment damage \\
\hline 6 & Significant & System performance is degraded with minor damage \\
\hline 5 & Moderate & Moderate effect on system performance which requires system repair \\
\hline 4 & Low & Small effect on system performance without requiring system repair \\
\hline 3 & Minor & Insignificant effect on system performance \\
\hline 2 & Very Minor & Very insignificant effect on system performance \\
\hline 1 & None & No effect \\
\hline
\end{tabular}


Table 6. Conventional crisp ratings for detection of a failure (D) [28-30, 34, 35, 57, 134, 136, 201, 239]

\begin{tabular}{|c|c|c|}
\hline Rank & Detection & Description \\
\hline 10 & $\begin{array}{l}\text { Absolutely } \\
\text { impossible }\end{array}$ & $\begin{array}{l}\text { Design control will not be able to detect a potential cause and consequent } \\
\text { failure mode }\end{array}$ \\
\hline 9 & Very remote & $\begin{array}{l}\text { Very remote chance of detection of a potential cause and consequent failure } \\
\text { mode by the design control }\end{array}$ \\
\hline 8 & Remote & $\begin{array}{l}\text { Remote chance of detection of a potential cause and consequent failure mode } \\
\text { by the design control }\end{array}$ \\
\hline 7 & Very low & $\begin{array}{l}\text { Possibility of detection of a potential cause and consequent failure mode by the } \\
\text { design control is very low }\end{array}$ \\
\hline 6 & Low & $\begin{array}{l}\text { Chance is low that the design control will detect a potential cause and } \\
\text { consequent failure mode }\end{array}$ \\
\hline 5 & Moderate & $\begin{array}{l}\text { Moderate chance of detection of a potential cause and consequent failure mode } \\
\text { by the design control }\end{array}$ \\
\hline 4 & Moderately high & $\begin{array}{l}\text { Chance is moderately high that the design control will detect a potential } \\
\text { cause/mechanism and consequent failure mode }\end{array}$ \\
\hline 3 & High & $\begin{array}{l}\text { Chance is high that the design control will detect a potential cause and } \\
\text { consequent failure mode }\end{array}$ \\
\hline 2 & Very high & $\begin{array}{l}\text { Chance of detection of a potential cause and consequent failure mode by the } \\
\text { design control is very high }\end{array}$ \\
\hline 1 & Almost certain & $\begin{array}{l}\text { It is almost certain that the design control will detect a potential cause and } \\
\text { consequent failure mode }\end{array}$ \\
\hline
\end{tabular}

Although FMEA is widely used, limitations have been reported in [24, 136, 137, 194, 257], in particular questions raised about the validity of RPN calculation. In Table 4, we can see that probability values are used to rank for occurrence of failure $(\mathrm{O})$, in a function which is non-linear. On the other hand, tables 5 and 6 show that qualitative information is used to quantitatively rank the severity (S) and detectability (D) of failure. It is evident that although the RPN calculation is a quantitative process, it is largely based on subjective qualitative assessments, which in turn casts doubts on the accuracy of results. A second issue to note is that an identical value of RPN could be produced for various sets of $\mathrm{O}, \mathrm{S}$, and $\mathrm{D}$, although their risk implication may not be the same $[15,172]$. For example, values $2,3,4$ and 4, 1, 6 for O, S, and D respectively will produce the same RPN value of 24 . Finally, it is not clear why the three risk factors should always be considered equally important.

To overcome those limitations, methods based on fuzzy logic have been proposed in [24, 62, 137, 239, 280]. A comprehensive list of fuzzy set theory based FMEA approaches developed till 2012 is available in [137, 239]. Since 2012, some new developments and new applications of the fuzzy FMEA have been noticed. Table 7 lists those developments and application of fuzzy FMEA.

Table 7. Developments and Applications of fuzzy FMEA since 2012

\begin{tabular}{ll}
\hline \multicolumn{1}{c}{ Category } & \multicolumn{1}{c}{ Papers } \\
\hline $\begin{array}{l}\text { New developments in } \\
\text { fuzzy set based }\end{array}$ & $\begin{array}{l}\text { Zhou and Thai [286], Ahmadi } \text { et al. [4], Liu, Liu, and Lin [136], Liu } \text { et al.[130, 138], } \\
\text { FMEA }\end{array}$ \\
& Chandal and Maiti [143], Kharola and Singh [100], Vahdani, Salimi, and \\
& [76], Tooranloo and Ayatollah [219]. \\
Applications & Zaman et al.[279], Dinmohammadi and Shafiee [44], Zhou and Thai [286], Dağsuyu \\
& et al.[39], Adar et al.[2], Ahmadi et al. [4], Panchal and Kumar [167], Rachieru, \\
& Belu, and Anghel [183], Kahraman, Kaya, and Şenvar [97], Yeh and Chen [263], \\
& Wessiani and Sarwoko [244], Helvacioglu and Ozen [78]. \\
\hline
\end{tabular}


In fuzzy FMEA, fuzzy if-then rules and expert judgments are used for risk prioritization of failure modes. The idea is to represent $\mathrm{O}, \mathrm{S}$, and $\mathrm{D}$ using linguistic variables and rank them using fuzzy numbers (e.g., trapezoidal fuzzy numbers) instead of crisp numbers. To do so, the first step is to define membership functions for the three risk factors $\mathrm{O}, \mathrm{S}$, and $\mathrm{D}$. Once membership functions are defined, each risk factor can be represented by linguistic variables. After that, expert judgment can be collected regarding the three risk factors in the form of linguistic terms. These linguistic terms are integrated in the fuzzy rule base to produce linguistic term representing the RPN. The next step is to define if-then rules to map the expert judgment regarding failure modes to fuzzy numbers. Given that the rule base may contain hundreds of rules, which can make the fuzzy FMEA process tedious, approaches have been developed to reduce the fuzzy rule base. In [172], initially 125 fuzzy if-then rules were generated and these rules were further combined and reduced to 25 rules. For example, in [70], [71], and [72], the authors have reduced 125 fuzzy if-then rules to 6, 14, and 16 rules, respectively. 27 fuzzy if-then rules were used in the approach proposed in [202].

To avoid the cumbersome process of creating large fuzzy rule bases, Wang et al. [239] have proposed the use of fuzzy weighted geometric mean for risk evaluation and prioritization of failure modes in FMEA. In this approach, the authors treated the risk factors $\mathrm{O}, \mathrm{S}$, and $\mathrm{D}$ as fuzzy variables and the fuzzy RPNs were evaluated as fuzzy weighted geometric means of the fuzzy values of $\mathrm{O}, \mathrm{S}$, and $\mathrm{D}$. For illustrative purpose, consider the linguistic variables and fuzzy numbers shown in Tables 8-10 to represent the O, S, and D, firstly used in [239]. As seen from these tables, trapezoidal and triangular fuzzy numbers were used to represent the fuzzy values of risk factors. In order to take the relative importance of the risk factors into account, the fuzzy weights for the relative importance of the risk factors are used as shown in Table 11.

Table 8. Fuzzy ratings for the occurrence of failure (O) [239]

\begin{tabular}{lll}
\hline \multicolumn{1}{c}{ Rating } & Frequency of Failure Occurrence & Fuzzy number \\
\hline Very high $(\mathrm{VH})$ & Failure is almost inevitable & $(8,9,10,10)$ \\
High $(\mathrm{H})$ & Repeated failures & $(6,7,8,9)$ \\
Moderate $(\mathrm{M})$ & Occasional failures & $(3,4,6,7)$ \\
Low $(\mathrm{L})$ & Relatively few failures & $(1,2,3,4)$ \\
Remote $(\mathrm{R})$ & Failure is unlikely & $(1,1,2,3)$ \\
\hline
\end{tabular}


Table 9. Fuzzy ratings for severity of a failure (S) [239]

\begin{tabular}{lll}
\hline \multicolumn{1}{c}{ Rating } & \multicolumn{1}{c}{ Severity of effect } & Fuzzy Number \\
\hline $\begin{array}{l}\text { Hazardous without } \\
\text { warning (HWOW) }\end{array}$ & $\begin{array}{l}\text { Very high severity ranking } \\
\text { without warning }\end{array}$ & $(9,10,10)$ \\
Hazardous with warning & $\begin{array}{l}\text { Very high severity ranking with } \\
\text { warning }\end{array}$ & $(8,9,10)$ \\
Very high (VH) & $\begin{array}{l}\text { System inoperable with } \\
\text { destructive failure }\end{array}$ & $(7,8,9)$ \\
High (H) & $\begin{array}{l}\text { System inoperable with equipment } \\
\text { damage }\end{array}$ & $(6,7,8)$ \\
Moderate (M) & $\begin{array}{l}\text { System inoperable with minor } \\
\text { damage }\end{array}$ & $(5,6,7)$ \\
Low (L) & $\begin{array}{l}\text { System inoperable without } \\
\text { damage }\end{array}$ & $(4,5,6)$ \\
Very low (VL) & $\begin{array}{l}\text { System operable with significant } \\
\text { degradation of performance }\end{array}$ & $(3,4,5)$ \\
Minor (MR) & $\begin{array}{l}\text { System operable with some } \\
\text { degradation of performance }\end{array}$ & $(2,3,4)$ \\
Very minor (VMR) & $\begin{array}{l}\text { System operable with minimal } \\
\text { interference }\end{array}$ & $(1,2,3)$ \\
None (N) & No effect & $(1,1,2)$ \\
\hline
\end{tabular}

Table 10. Fuzzy ratings for detection of a failure (D) [239]

\begin{tabular}{lll}
\hline \multicolumn{1}{c}{ Rating } & Likelihood of detection & Fuzzy number \\
\hline Absolute uncertainty (AU) & No chance & $(9,10,10)$ \\
Very remote (VR) & Very remote chance & $(8,9,10)$ \\
Remote (R) & Remote chance & $(7,8,9)$ \\
Very low (VL) & Very low chance & $(6,7,8)$ \\
Low (L) & Low chance & $(5,6,7)$ \\
Moderate (M) & Moderate chance & $(4,5,6)$ \\
Moderately high (MH) & Moderately high chance & $(3,4,5)$ \\
High (H) & High chance & $(2,3,4)$ \\
Very high (VH) & Very high chance & $(1,2,3)$ \\
Almost certain (AC) & Almost certain & $(1,1,2)$ \\
\hline
\end{tabular}

Table 11. Fuzzy weights for the relative importance of risk factors [239]

\begin{tabular}{ll}
\hline Weights in Linguistic Term & \multicolumn{1}{c}{ Fuzzy Number } \\
\hline Very low (VL) & $(0,0,0.25)$ \\
Low (L) & $(0,0.25,0.50)$ \\
Medium (M) & $(0.25,0.50,0.75)$ \\
High (H) & $(0.50) .75,1.0)$, \\
Very high (VH) & $(0.75,1.0,1.0)$ \\
\hline
\end{tabular}


After defining all the fuzzy parameters for the risk factors, the authors in [239] consider the priority of $n$ failure modes, $F M_{i}(i=1,2,3, \ldots, n)$, to be evaluated by a group of $m$ team members, $M_{j}(j=1,2,3, \ldots, m)$. In this context $\tilde{R}_{i j}^{O}=\left(R_{i j L}^{O}, R_{i j M_{1}}^{O}, R_{i j M_{2}}^{O}, R_{i j U}^{O}\right), \widetilde{R}_{i j}^{S}=\left(R_{i j L}^{S}, R_{i j M}^{S}, R_{i j U}^{S}\right)$, and $\tilde{R}_{i j}^{D}=\left(R_{i j L}^{D}, R_{i j M}^{D}, R_{i j U}^{D}\right)$ are the fuzzy ratings and $\widetilde{w}_{j}^{O}=\left(w_{j L}^{O}, w_{j M}^{O}, w_{j U}^{O}\right), \widetilde{w}_{j}^{S}=\left(w_{j L}^{S}, w_{j M}^{S}, w_{j U}^{S}\right)$, and $\widetilde{w}_{j}^{D}=\left(w_{j L}^{D}, w_{j M}^{D}, w_{j U}^{D}\right)$ are the fuzzy weights of $\mathrm{O}, \mathrm{S}$, and $\mathrm{D}$ respectively for the $i^{\text {th }}$ failure mode provided by the $j^{\text {th }}$ member of the team. $h_{j}$ is the relative importance weights of the $m$ team members, where $\sum_{j=1}^{m} h_{j}=1$ and $h_{j}>0$.

Given the above, the aggregated fuzzy ratings $\widetilde{R}_{i}^{O}, \widetilde{R}_{i}^{S}$, and $\widetilde{R}_{i}^{D}$ and aggregated fuzzy weights $\widetilde{w}^{O}, \widetilde{w}^{S}$, and $\widetilde{w}^{D}$ for the risk factors $\mathrm{O}, \mathrm{S}$, and $\mathrm{D}$ of the failure mode $i$ are calculated as follows:

$$
\begin{aligned}
\tilde{R}_{i}^{O}=\sum_{j=1}^{m} h_{j} \tilde{R}_{i j}^{O}=\left(\sum_{j=1}^{m} h_{j} R_{i j L}^{O}, \sum_{j=1}^{m} h_{j} R_{i j M_{1}}^{O}, \sum_{j=1}^{m} h_{j} R_{i j M_{2}}^{O}, \sum_{j=1}^{m} h_{j} R_{i j U}^{O}\right) \\
\tilde{R}_{i}^{S}=\sum_{j=1}^{m} h_{j} \tilde{R}_{i j}^{S}=\left(\sum_{j=1}^{m} h_{j} R_{i j L}^{S}, \sum_{j=1}^{m} h_{j} R_{i j M}^{S}, \sum_{j=1}^{m} h_{j} R_{i j U}^{S}\right) \\
\tilde{R}_{i}^{D}=\sum_{j=1}^{m} h_{j} \tilde{R}_{i j}^{D}=\left(\sum_{j=1}^{m} h_{j} R_{i j L}^{D}, \sum_{j=1}^{m} h_{j} R_{i j M}^{D}, \sum_{j=1}^{m} h_{j} R_{i j U}^{D}\right) \\
\widetilde{w}^{O}=\sum_{j=1}^{m} h_{j} \widetilde{w}_{j}^{O}=\left(\sum_{j=1}^{m} h_{j} w_{j L}^{O}, \sum_{j=1}^{m} h_{j} w_{j M}^{O}, \sum_{j=1}^{m} h_{j} w_{j U}^{O}\right) \\
\widetilde{w}^{S}=\sum_{j=1}^{m} h_{j} \widetilde{w}_{j}^{S}=\left(\sum_{j=1}^{m} h_{j} w_{j L}^{S}, \sum_{j=1}^{m} h_{j} w_{j M}^{S}, \sum_{j=1}^{m} h_{j} w_{j U}^{S}\right) \\
\widetilde{w}^{D}=\sum_{j=1}^{m} h_{j} \widetilde{w}_{j}^{D}=\left(\sum_{j=1}^{m} h_{j} w_{j L}^{D}, \sum_{j=1}^{m} h_{j} w_{j M}^{D}, \sum_{j=1}^{m} h_{j} w_{j U}^{D}\right)
\end{aligned}
$$

The fuzzy risk priority number (FRPN) of the failure mode $i$ is obtained using the following formula.

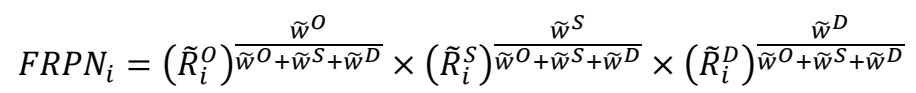

The authors in [239] also defined formulas for obtaining $\alpha$-level sets of the FRPNs and the defuzzified value of FRPNs.

For illustration, consider that the FMEA team consists of five members. The relative weights of the members and their opinions regarding the fuzzy ratings and weights for three risk factors of failure mode 1 is shown in Table 12. By using equations (27)-(32) and values from tables 8-12, the aggregated ratings for O, S, and D are $(4.7,5.7,7.2,8.1),(6.05,7.05,8.05)$, and $(5.95,6.95,7.95)$ respectively. The aggregated importance weights for $\mathrm{O}, \mathrm{S}$, and D are $(0.425,0.675,0.8625),(0.6125,0.8625,1)$, and $(0.0625,0.3125,0.5625)$. Using the formulas defined in [239] the defuzzified value of FRPN for failure mode 1 is 6.7561 . The FRPNs and their corresponding defuzzified values for other failure modes can be obtained in the same way. Once all the defuzzified values of FRPNs for all the failure modes are calculated, they can be ranked based on these values. 
Table 12. Fuzzy ratings and weights for three risk factors for failure mode 1

\begin{tabular}{ccccc}
\hline Risk Factors & $\begin{array}{c}\text { Team } \\
\text { Members }\end{array}$ & $\begin{array}{c}\text { Relative Weights } \\
\text { of Team Members }\end{array}$ & $\begin{array}{c}\text { Ratings for } \\
\text { Failure mode 1 }\end{array}$ & $\begin{array}{c}\text { Weights for } \\
\text { failure mode 1 }\end{array}$ \\
\hline \multirow{3}{*}{$\begin{array}{c}\text { Occurrence } \\
\text { (O) }\end{array}$} & $\mathrm{TM}_{1}$ & 0.15 & $\mathrm{H}$ & $\mathrm{M}$ \\
& $\mathrm{TM}_{2}$ & 0.20 & $\mathrm{M}$ & $\mathrm{H}$ \\
& $\mathrm{TM}_{3}$ & 0.30 & $\mathrm{M}$ & $\mathrm{M}$ \\
& $\mathrm{TM}_{4}$ & 0.25 & $\mathrm{H}$ & $\mathrm{VH}$ \\
& $\mathrm{TM}_{5}$ & 0.10 & $\mathrm{VH}$ & $\mathrm{M}$ \\
& $\mathrm{TM}_{1}$ & 0.15 & $\mathrm{H}$ & $\mathrm{VH}$ \\
Severity (S) & $\mathrm{TM}_{2}$ & 0.20 & $\mathrm{M}$ & $\mathrm{H}$ \\
& $\mathrm{TM}_{3}$ & 0.30 & $\mathrm{H}$ & $\mathrm{VH}$ \\
& $\mathrm{TM}_{4}$ & 0.25 & $\mathrm{VH}$ & $\mathrm{H}$ \\
& $\mathrm{TM}_{5}$ & 0.10 & $\mathrm{H}$ & $\mathrm{H}$ \\
& $\mathrm{TM}_{1}$ & 0.15 & $\mathrm{VL}$ & $\mathrm{L}$ \\
& $\mathrm{TM}_{2}$ & 0.20 & $\mathrm{R}$ & $\mathrm{L}$ \\
Detection (D) & $\mathrm{TM}_{3}$ & 0.30 & $\mathrm{R}$ & $\mathrm{L}$ \\
& $\mathrm{TM}_{4}$ & 0.25 & $\mathrm{MH}$ & $\mathrm{M}$ \\
& $\mathrm{TM}_{5}$ & 0.10 & $\mathrm{VR}$ & $\mathrm{L}$ \\
\hline
\end{tabular}

\section{Fuzzy Event Tree Analysis}

Event tree analysis (ETA) is a bottom-up, inductive analysis approach that projects the sequence of events in a potential accident scenario, given that an initiating event (system failure) has occurred. Event trees visually represent all event sequences that may follow a failure [6]. As seen in Fig. 5, an initiating hazardous event is followed by a series of events typically representing safety responses or safety barriers. The event tree then becomes a binary tree, where each branch either represents a success (true) or failure (false) of each one of those safety responses. If the probability of success of an event is $(\mathrm{P})$ then the probability of failure is (1-P). Event trees can be analysed both qualitatively and quantitatively. Qualitative analysis of an event tree identifies the potential consequences of the initiating event. Quantitative analysis of ETs estimates the likelihoods of the possible outcomes of the initiating event. A detail description of creating and analysing event trees for process system is available in [144].
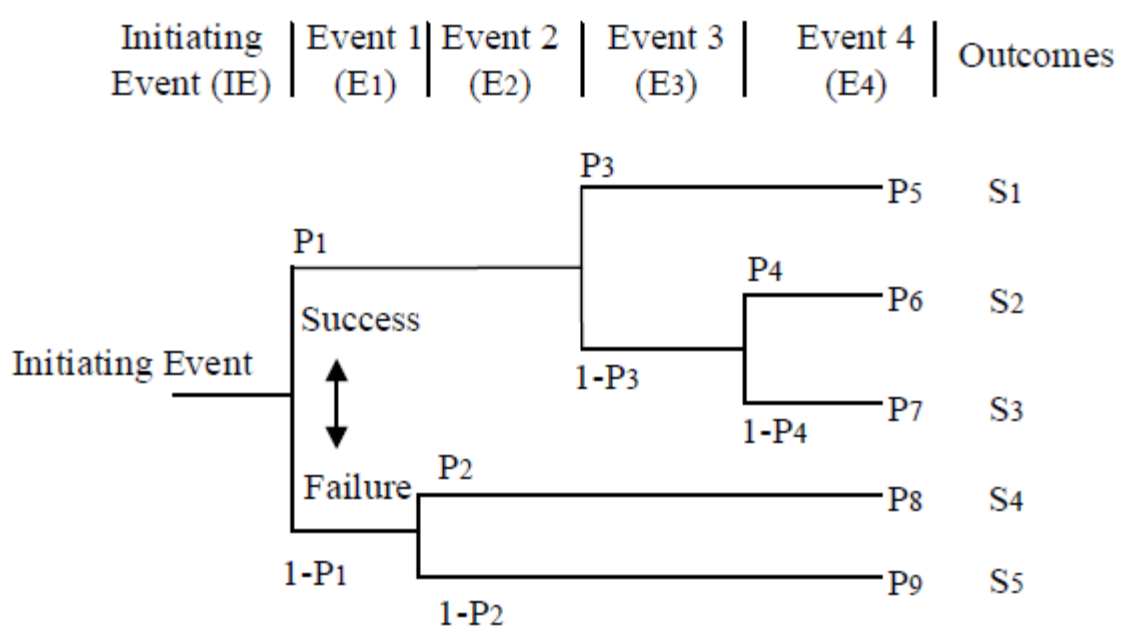

Fig. 5. Example of an event tree 
In quantitative analysis of ETA, crisp values are used to represent the event probabilities to estimate outcome events probability [99]. Such crisp values are not always available so a number of researches [37, 53, 84, 98, 99] deal with uncertainty drawing from fuzzy set theory. In fuzzy ETA, event probabilities are represented as fuzzy numbers and all the calculations are done based on these fuzzy numbers, hence the probabilities of the possible outcomes are also obtained as fuzzy numbers. These fuzzy probability values are then defuzzified to obtain a crisp value. It is important to note that the fuzzy data approximation process is same for both fuzzy FTA and fuzzy ETA. Similar to the fuzzy FTA, it is also possible to perform sensitivity (importance) analysis of the events.

Fuzzy arithmetic operations are utilised to estimate the outcome event probability. In fuzzy ETA, multiplication and addition are the two operations that are essentially required to calculate the outcome probability [188]. Authors in [53-55, 89] have defined these operations for the trapezoidal representation of the fuzzy numbers. For illustration purpose, consider the event tree in Fig. 5. In this tree, in addition to the initiating event, there are four other events (E1, E2, E3 and E4), and there are five possible outcomes (S1, S2, S3, S4, and S5). Assume that after following all the processes described in section 2 for fuzzy data definition and collection, the fuzzy probabilities of the events E1, E2, E3, and E4 in triangular forms are: $\tilde{P}_{1}=\left\{a_{1}, b_{1}, c_{1}\right\}, \tilde{P}_{2}=\left\{a_{2}, b_{2}, c_{2}\right\}, \tilde{P}_{3}=$ $\left\{a_{3}, b_{3}, c_{3}\right\}$, and $\tilde{P}_{4}=\left\{a_{4}, b_{4}, c_{4}\right\}$, respectively.

According to Fig. 5, the fuzzy probabilities of different outcomes can be obtained as:

$$
\begin{gathered}
\tilde{P}_{S 1}=\tilde{P}_{1} \otimes \tilde{P}_{3} \\
\tilde{P}_{S 2}=\tilde{P}_{1} \otimes\left(1-\tilde{P}_{3}\right) \otimes \tilde{P}_{4} \\
\tilde{P}_{S 3}=\tilde{P}_{1} \otimes\left(1-\tilde{P}_{3}\right) \otimes\left(1-\tilde{P}_{4}\right) \\
\tilde{P}_{S 4}=\left(1-\tilde{P}_{1}\right) \otimes \tilde{P}_{2} \\
\tilde{P}_{S 5}=\left(1-\tilde{P}_{1}\right) \otimes\left(1-\tilde{P}_{2}\right)
\end{gathered}
$$

In the above equations, the symbol $\otimes$ represents a fuzzy multiplication operation and the result of multiplication of two triangular fuzzy numbers is another triangular fuzzy number. If $k$ represents an accident scenario with fatalities, then its fuzzy probability is obtained as:

$$
\tilde{P}_{k}=\sum_{i=1}^{5} \tilde{P}_{S i}
$$

The probability of individual outcome and the probability of accident scenario with fatalities are all fuzzy numbers. These values could be defuzzified using the methods mentioned in section 2.4 to obtain crisp values.

\section{Other Approaches}

Other approaches to fuzzy safety and reliability assessment include, but not limited to Bayesian networks, Markov models, and Petri nets. Fuzzy set theory has also been used with these approaches to handle uncertainty in processes. This section reviews some of those approaches.

\subsection{Fuzzy Bayesian Network Approaches}

Bayesian networks $(\mathrm{BN})$ has gained popularity in this domain due to their ability to combine different sources of information to provide a global safety and reliability assessment and to provide methods of reasoning under uncertainty $[18,109]$. BNs are used in two different ways in safety and reliability assessment of systems. In the first way, the systems are modelled using BNs and then the analysis is performed on that model. Examples of such approaches are $[45,158,159,220]$. The second way is by transforming dependability artefacts such as fault 
trees into BNs. The approaches that fall into this category include [18, 20, 21, 93, 155]. All classical approaches use crisp probability values to represent the probability of events but recently the Bayesian approach has been generalised to accommodate fuzzy data [58, 66, 164, 214].

The key idea of the fuzzy Bayesian approach is to use fuzzy numbers to represent the prior/conditional probabilities of the root/intermediate nodes [86, 126,193, 245, 246, 255]. Subsequent analysis on the BN model uses this data. Different approaches consider different system parameters as fuzzy. For instance, in [64, 86, 215, 234, 245, 246], the failure data is fuzzy, while in Li et al. [122] quantify human reliability using triangular fuzzy numbers. Simon and Weber [208] considered system states as fuzzy, while Yanfu and Min [255] integrated fault trees with Bayesian networks, i.e., they translated fuzzy fault trees into BNs for reliability evaluation. Fuzzy failure probabilities of basic events of fault trees were represented in the form: (high, medium, low), which were used as prior probabilities for the root nodes in the BN model. Accordingly, rules were defined to calculate conditional fuzzy probabilities for the intermediate nodes, which are logic gates in the fault tree. In a classic BN model, the probability of a logic gate is determined as being 0 or 1 because the outcome of a gate can either be true or false with certainty. For illustration of this approach, consider the intermediate event $A 1$ in the fault tree of Fig. 3. This is an AND gate with two inputs $X 1$ and $X 2$. The BN model of this intermediate event is shown in Fig. 6. As seen in the figure, the fuzzy failure probabilities of the events $X 1$ and $X 2$ are considered to be $(0.2$, $0.2,0.6)$ and $(0.35,0.35,0.3)$, respectively. The conditional probability of the intermediate node $A 1$ is populated based on the rules defined in [255]. Now, running a query on the node $A 1$ would give us the fuzzy probability of the event $A 1$ given the fuzzy probability of the events $X 1$ and $X 2$. For this particular example, the fuzzy probability of $A 1$ obtained is $(0.12901,0.37654,0.49445)$.

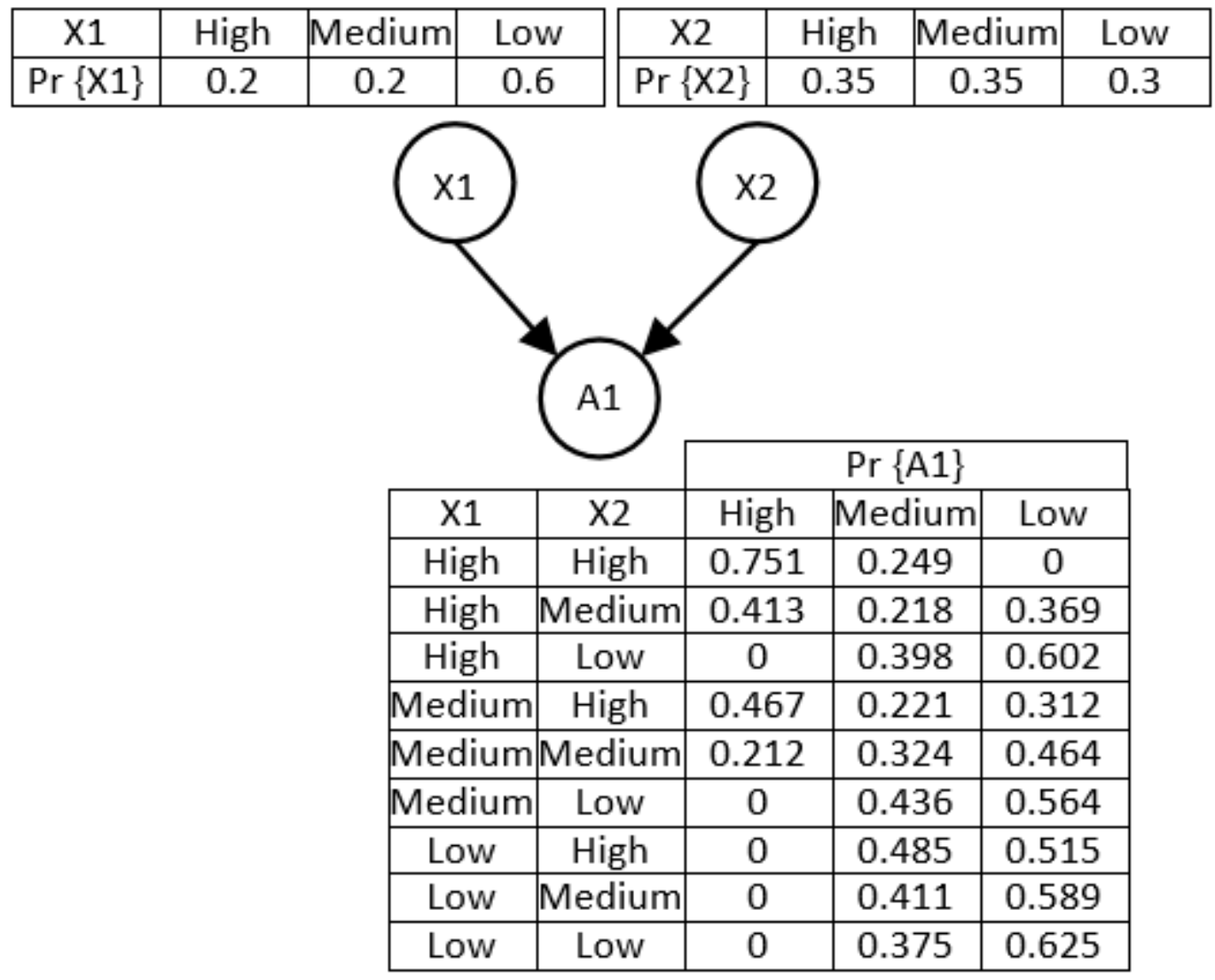

Fig. 6. Fuzzy Bayesian Network example

In this area of BNs, there are also simpler approaches where fuzzy set theory is first used separately to obtain unknown failure data in a fuzzy form based on expert judgment and then this data is defuzzified to get crisp values. Subsequently, classical BNs are used to make decisions using the crisp data, e.g. in Yan et al. [254]. Fuzzy Bayesian network approaches have been applied for safety and reliability analysis in a variety of 
industries such as marine and offshore industry [50, 186], process industry [254, 260], and production systems [68].

\subsection{Fuzzy Markov Chain Approaches}

Markov model analysis is a state-transition based graphical modelling technique, which can capture the dynamic behaviour of systems. Generally, a Markov model of a system consists of all possible states that the system can be in, the transitions between the states, and numerical values defining the rate of each transition. In safety and reliability analysis, the states in the Markov model incorporate information related to component failures, sequence of failures, and spare allocations. The transition rates are either failure or repair rate of components. Based on this information, differential equations of states are obtained and results are obtained by solving these equations.

Classical Markov chains assume the availability of exact transition rates/probabilities. To deal with uncertainty fuzzy Markov chain approaches have been proposed in [11, 12, 25, 106]. In these approaches, the transition rates/probabilities as well as states can be considered as fuzzy. In Markov models with fuzzy transition rates, two methods are used to calculate system reliability. In the first, the matrix of Markov equations is augmented with fuzzy membership functions where transition rates are unknown. Fuzzy arithmetic operations are then used to complete the Markov process calculation. This method requires complex calculations involving fuzzy numbers, hence it is computationally demanding. The second way is to determine the reliability indices as functions of transition rates, and subsequently use fuzzy data in these functions to evaluate fuzzy reliability indices. One issue with this approach is that it requires explicit mathematical equations, which may not be practical in large systems with complex interactions between components.

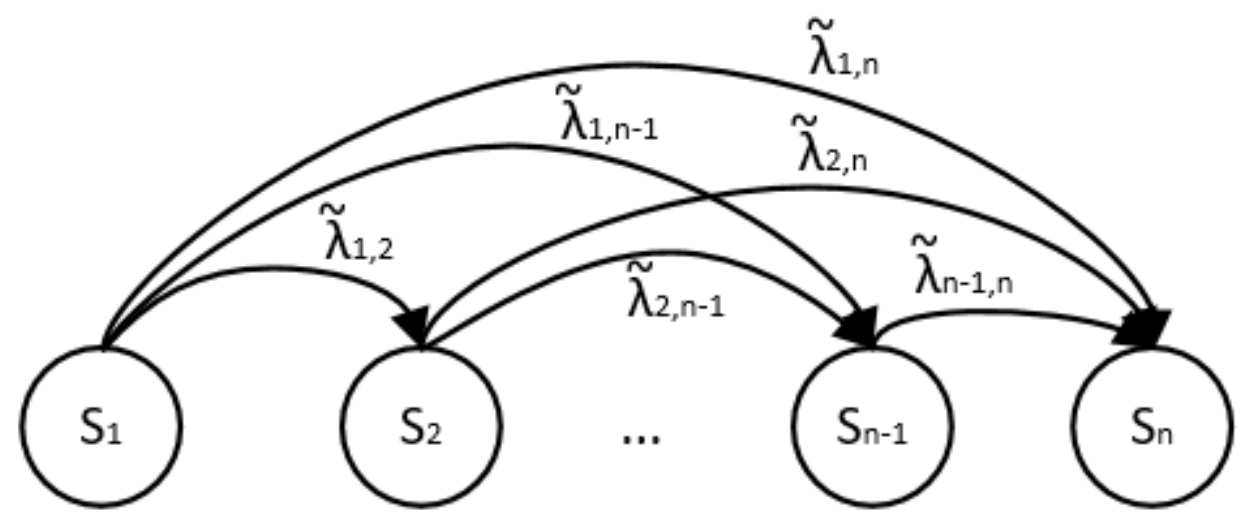

Fig.7. Fuzzy Markov chain example

For illustration, consider the Markov model in Fig. 7. The above model represents a system with $n$ states: $\left\{S_{1}, S_{2}, \cdots, S_{n-1}, S_{n}\right\}$. The fuzzy number $\tilde{\lambda}_{i, j}$ represents the fuzzy transition rate from state $S_{i}$ to state $S_{j}$. The fuzzy state transition rate matrix can be written as follows:

$$
\widetilde{M}=\left[\begin{array}{ccccc}
\tilde{\lambda}_{1,1} & \tilde{\lambda}_{1,2} & \cdots & \tilde{\lambda}_{1, n-1} & \tilde{\lambda}_{1, n} \\
\tilde{\lambda}_{2,1} & \tilde{\lambda}_{2,2} & \cdots & \tilde{\lambda}_{2, n-1} & \tilde{\lambda}_{2, n} \\
\vdots & \vdots & \ddots & \cdots & \vdots \\
\tilde{\lambda}_{n, 1} & \tilde{\lambda}_{n, 2} & \cdots & \tilde{\lambda}_{n, n-1} & \tilde{\lambda}_{n, n}
\end{array}\right]
$$

If $\tilde{P}_{i}(t)$ represents the fuzzy probability of the system being in state $S_{i}$ at time $t$, then the differential equations of the Markov model corresponding in the above matrix are as follows: 


$$
\left\{\begin{array}{l}
\frac{d \tilde{P}_{1}(t)}{d t}=-\tilde{P}_{1}(t) \sum_{j=1}^{n} \tilde{\lambda}_{1, j} \\
\vdots \\
\frac{d \tilde{P}_{i}(t)}{d t}=\sum_{j=1}^{i-1} \tilde{P}_{j}(t) \tilde{\lambda}_{1, j}-\sum_{j=i+1}^{n} \tilde{P}_{i}(t) \tilde{\lambda}_{i, j}, \quad 1<i<n, t \geq 0 \\
\vdots \\
\frac{d \tilde{P}_{n}(t)}{d t}=-\sum_{j=1}^{n-1} \tilde{P}_{j}(t) \tilde{\lambda}_{j, n}
\end{array}\right.
$$

Each equation in the above set of equations corresponds to a state in the Markov model. The above equations can be solved to obtain the fuzzy probability of the system being if different states.

Leuschen, Walker, and Cavallaro [119] proposed a fuzzy Markov model approach to quantify reliability of robots. In this approach, both states and the transition rates were considered to be fuzzy. Variants have been described in [63, 107, 147, 174, 218]. Fuzzy Markov model approaches have also been applied to a variety of systems, such as communication networks [173], power grids and smart meters [16, 77, 290], and degradable computing systems [170].

\subsection{Fuzzy Petri Net Approaches}

Petri nets have been used both as a standalone approach and as a part of model transformation approaches. Early uses in system safety and reliability assessment as a standalone approach can be found in [120, 191, 204]. Model transformation approaches where Petri nets were used for safety and reliability analysis include $[19,38,88,94$, $95,142,187]$. Classical PNs require exact failure rate/probability, repair rate and other dependability related data. To address uncertainty, fuzzy Petri nets have been proposed. While an overview is available in [235, 287], few applications have been reported in safety and reliability analysis. In 2001, Knezevic and Odoom [104] used PN models for qualitative analysis of systems and then fuzzy set theory on failure/repair rates for quantitative analysis. Garg [61] combined Petri nets with intuitionistic fuzzy sets. PN was used for qualitative modelling of behaviour of systems, while for quantitative analysis, failure/repair rates are represented by intuitionistic fuzzy numbers of triangular membership function. Wu et al. [247] proposed a method combining FTA and fuzzy reasoning PN (FRPN) for reliability analysis of a solar array system. The root causes of the failure of solar array were determined using FTA. The FT was then translated into FRPN, which was used for fault propagation studies and reliability analysis. This method was extended in [248] and applied for reliability apportionment of solar array of spacecraft.

A FRPN is represented as an eight-tuple [60] model $N=(P, R, I, O, H, \theta, \gamma, C)$, where:

1. $P=\left\{p_{1}, p_{2}, \ldots, p_{n}\right\}, 1 \times n$; is a finite set of places (propositions);

2. $R=\left\{r_{1}, r_{2}, \ldots, r_{m}\right\}, 1 \times m$; is a finite set of transitions (rules);

3. I: $P \times R \rightarrow\{0,1\}, n \times m$; a finite set of directed arcs from propositions to rules;

4. $O: P \times R \rightarrow\{0,1\}, n \times m$; a finite set of directed arcs from rules to propositions;

5. $H=P \times R \rightarrow\{0,1\}, n \times m$; complementary arcs from propositions to rules;

6. $\theta=\left\{\theta_{1}, \theta_{2}, \ldots, \theta_{n}\right\}^{T}, \theta_{i} \in[0,1], n \times 1$; is the truth degree vector which represents the fuzzy possibility of the failures;

7. $\gamma: P \rightarrow\{0,1\}, \gamma=\left\{\gamma_{1}, \gamma_{2}, \ldots, \gamma_{n}\right\}^{T}, n \times 1$; is the marking vector which shows the failure propagation in the model. A place $p_{i}$ will get a token if the element $\gamma_{i}=1$;

8. $C=\operatorname{diag}\left\{c_{1}, c_{2}, \ldots, c_{m}\right\}, 1 \times m$; is the confidence of $r_{j}$.

A FRPN model can be simulated automatically based on the algorithm proposed in [60] showing the failure propagation in the model. The flowchart of the FRPN algorithm is shown in Fig. 8 and the truth degree propagation rules are shown in Fig. 9. The mathematical formulation of an FRPN model can be found in [60]: 
- $\oplus: A \oplus B=D$, where $\mathrm{A}, \mathrm{B}$, and $\mathrm{D}$ are $m \times n$ dimensional matrices and each entry in $\mathrm{D}$ is $d_{i j}=$ $\max \left\{a_{i j}, b_{i j}\right\}$

- $\otimes: A \otimes B=D$, where $\mathrm{A}, \mathrm{B}$, and $\mathrm{D}$ are $m \times p, p \times n$, and $m \times n$ dimensional matrices and each entry in $\mathrm{D}$ is $d_{i j}=\max _{1 \leq k \leq p}\left\{a_{i k} \cdot b_{k j}\right\}$

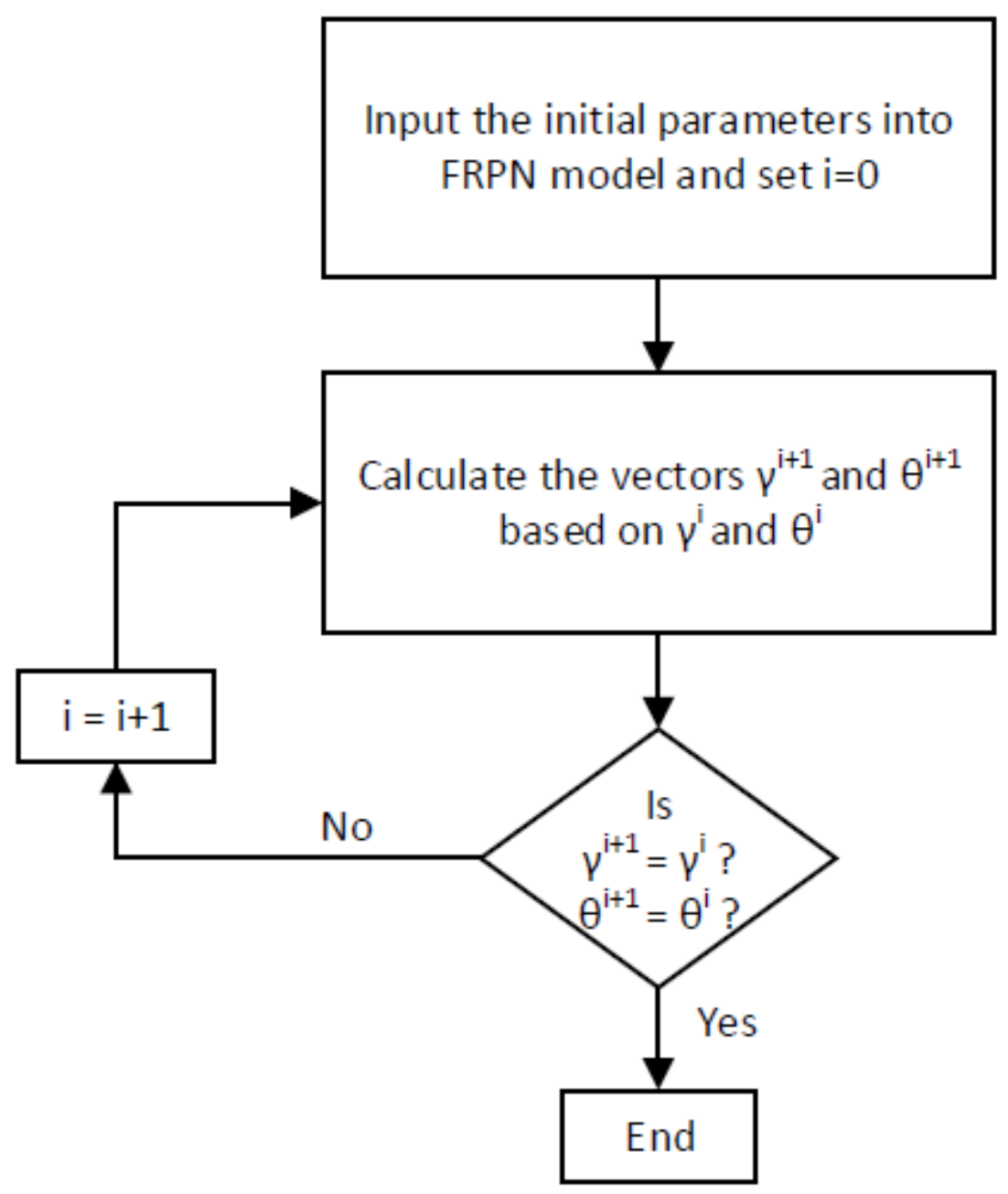

Fig. 8. Flow chat of FRPN algorithm [248] 


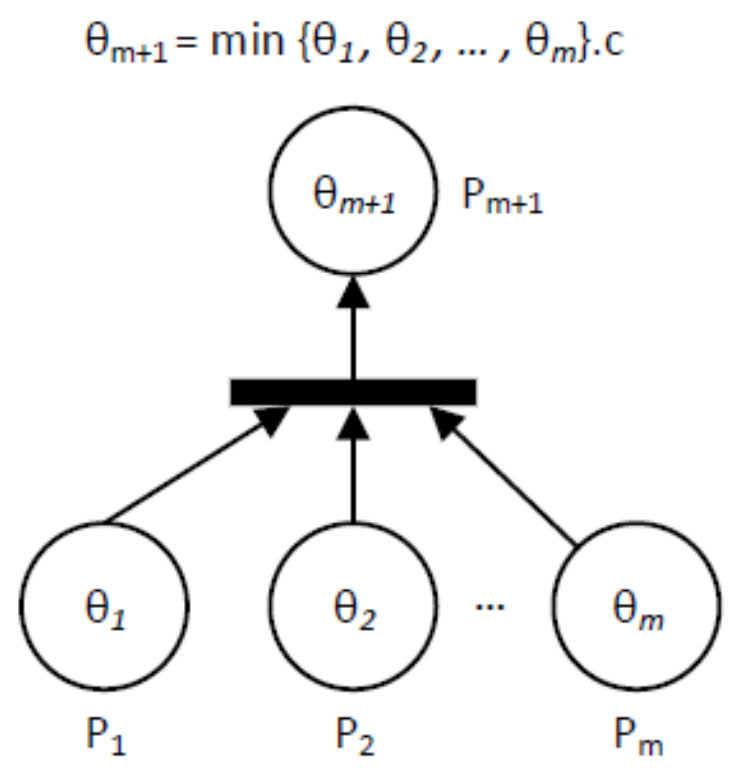

(a) AND transition

$$
\theta_{\mathrm{m}+1}=\max \left\{\mathrm{c}_{1} \theta_{1}, \mathrm{c}_{2} \theta_{2}, \ldots, \mathrm{c}_{m} \theta_{m}\right\}
$$

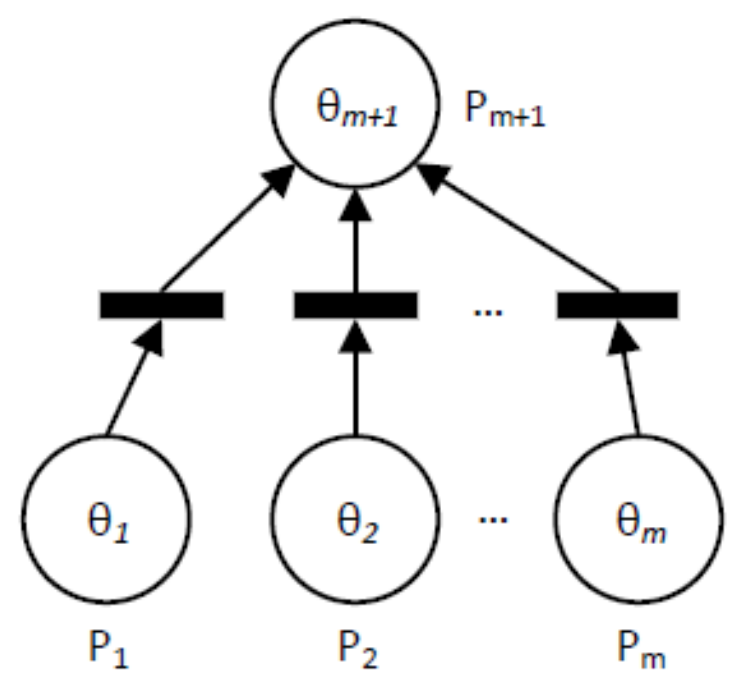

(b) OR transition

Fig. 9. Truth degree propagation [247]

The firing and control vectors are defined as follows [60]:

$$
\begin{gathered}
\mu_{m \times 1}^{k}=1_{m \times 1}-(I+H)^{T} \otimes \bar{\gamma}^{k} \\
\rho_{m \times 1}^{k}=1_{m \times 1}-\left(I^{T} \otimes\left(\bar{\gamma}^{k} \oplus \bar{\theta}^{k}\right)\right) \oplus\left(H^{T} \otimes\left(\bar{\gamma}^{k} \oplus \bar{\theta}^{k}\right)\right)
\end{gathered}
$$

Where

$$
\begin{aligned}
\bar{\theta}^{k} & =1_{m \times 1}-\theta^{k} \\
\bar{\gamma}^{k} & =1_{m \times 1}-\gamma^{k}
\end{aligned}
$$

The truth degree vector and the marking can be determined by

$$
\begin{aligned}
& \theta^{k+1}=\theta^{k} \oplus[(O . C) \otimes \rho] \\
& \gamma^{k+1}=\gamma^{k} \oplus[O \otimes \mu]
\end{aligned}
$$

For illustration purposes, consider the FRPN model in Fig. 10, where places $\mathrm{P}_{1}$ to $\mathrm{P}_{4}$ represents the failure events corresponding to different system components and place $\mathrm{P}_{7}$ represents the system failure. Assume that the initial truth degree vector is $\theta^{0}=(0.7,0.8,0.7,0.8,0,0,0)$, initial marking is $\gamma^{0}=(1,1,1,1,0,0,0)$, and the confidence for all the rules is 0.9 . Using these initial conditions, the FRPN model is simulated iteratively according to the flowchart of Fig. 8. The results of simulation are shown in table 13. The results show how the failure is propagated through the FRPN model. As seen from the table, the final truth degree of the top place $\left(\mathrm{P}_{7}\right)$ is 0.567 . That means the system failure possibility is 0.567 . 


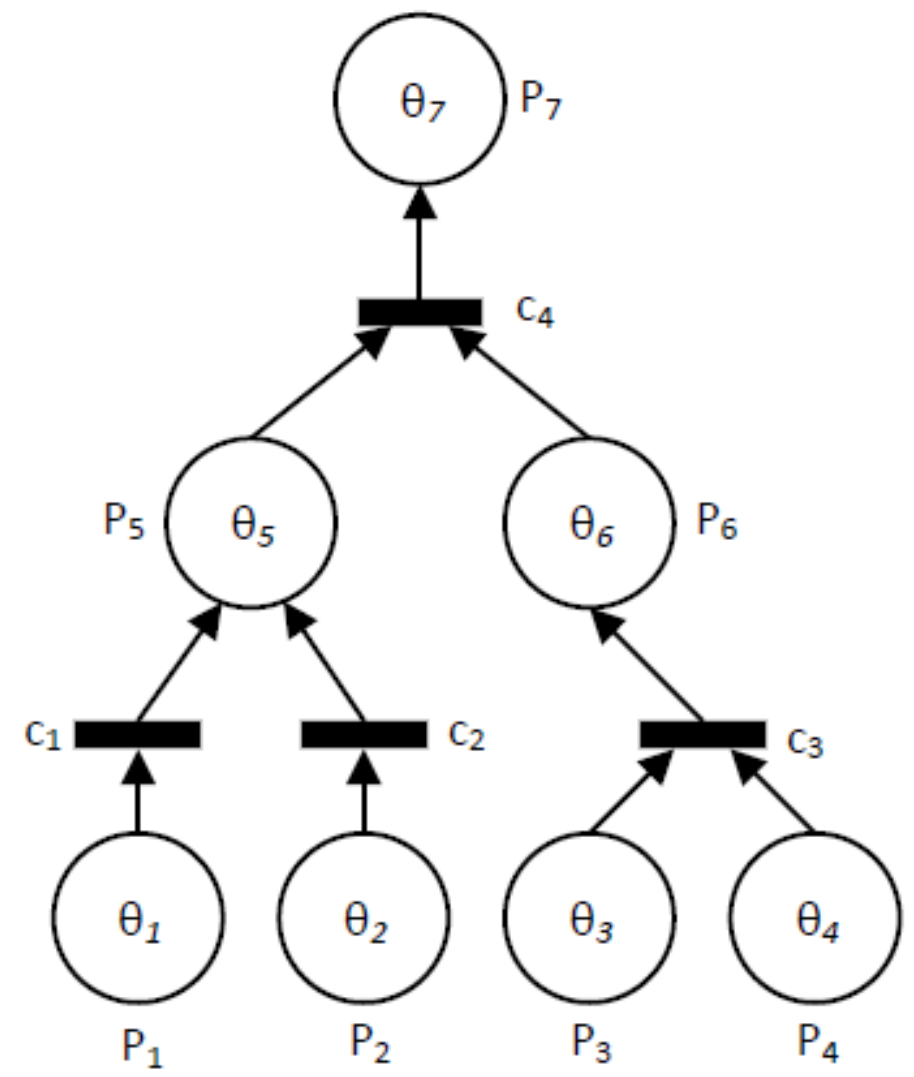

Fig. 10. An example FRPN model

Table 13. Results obtained by simulating the FRPN model in Fig. 10

\begin{tabular}{ccc}
\hline$i$ & $\gamma^{i}$ & $\theta^{i}$ \\
\hline 0 & $(1,1,1,1,0,0,0)$ & $(0.7,0.8,0.7,0.8,0,0,0)$ \\
1 & $(1,1,1,1,1,1,0)$ & $(0.7,0.8,0.7,0.8,0.72,0.63,0)$ \\
2 & $(1,1,1,1,1,1,1)$ & $(0.7,0.8,0.7,0.8,0.72,0.63,0.567)$ \\
3 & $(1,1,1,1,1,1,1)$ & $(0.7,0.8,0.7,0.8,0.72,0.63,0.567)$ \\
\hline
\end{tabular}

Sun et al. [212] used fuzzy Petri nets to create fault diagnosis models of electric power systems (EPS). By combining Petri nets with fuzzy set theory this approach allows the fault diagnosis of EPS when incomplete and uncertain alarm information of protective relays and circuit breakers is detected. The feasibility and effectiveness of this approach was illustrated through simulation. Fuzzy PNs have been used in [284] for fault diagnosis of power systems, where the temporal behaviour of the systems is taken into account. Liu et al. [133] combined fuzzy evidential reasoning (FER) and dynamic adaptive fuzzy Petri nets (DAFPNs) for fault detection and causal diagnosis. FER was used to identify abnormal events and the DAFPNs were used to determine the root causes and consequences of the abnormal events. Recently, Guo et al. [74] proposed a fuzzy Petri net based methodology for risk analysis of long-distance oil and gas transportation pipelines.

\section{Discussion and Future Outlook}

There is increasing recognition that unavailability of adequate failure data can undermine the efficacy and applicability of classical safety and reliability assessments. This literature review shows that fuzzy set theory has been applied quite extensively in this field of research to address unavailability, scarcity or uncertainty in data. In addition, concepts like fuzzy importance measures have allowed analysts to determine the relative contribution of different system components to the overall failure without relying on an exact estimation of 
system failure probability. The body of research we cited suggests that fuzzy set theory can enable us to draw helpful conclusions about safety and reliability even in the absence of concrete failure data. This could be useful in supporting an iterative design process by guiding the focus of future development on the most critical areas of the system architecture from early stages where data is scarce. However, it is important to emphasise that the inclusion of the concepts of fuzzy logic in the classical approaches would not increase the accuracy of the result where none previously existed, it just opens the avenue to perform safety and reliability analysis with uncertain data.

Some issues therefore require further research. Firstly, the review reveals that a wide variety of fuzzy membership functions has been used and they vary across application areas. There appears to be few guidelines available on how the shape of membership function should be selected and defined. As the definition of appropriate membership functions and fuzzy rules has significant impact on the outcomes of the analysis, it is worthwhile trying to define guidelines for selecting and defining membership functions for different application areas or systems. Secondly, most of the fuzzy logic based approaches define fuzzy failure data of components by considering that they can either be in failed or non-failed state. That means failed and non-failed states of systems and components are still defined in a crisp way, and only the failure probability data are treated as fuzzy. However, complex systems can also be in states that lie in-between success and failure, degraded states and transient failure states in which spontaneous recovery and again failure are possible. So far, very little research has been done on how to deal with these situations by using appropriate fuzzy definition of failed and non-failed state of systems. In addition, further research need to be performed to evaluate fuzzy reliability of concurrent and multi-state systems.

The most pervasive use of fuzzy set theory in safety and reliability evaluation is with fault tree analysis. Most fuzzy fault tree analysis approaches consider that the system components are non-repairable. However, this assumption is very restrictive and unrealistic. Therefore, in the future, it is worth taking repairability of the systems into account during fuzzy FTA. State space-based methods such as Markov chains and Petri nets-based methods usually consider system repairability during reliability evaluation. However, in general, these approaches suffer from the state-space explosion problem while modelling moderately complex systems. As a result, their applicability is limited to small-scale systems. In the past, modularized techniques [33, 73, 87, 264] have been developed to alleviate the state-space explosion problem, but those techniques work only for systems with precise failure data. For this reason, it would be worthwhile performing research either to adapt the existing modularized techniques for the use of fuzzy set theory or to develop new approaches for the modularized analysis of systems with fuzzy data. This will improve the scalability of the approaches.

It is important to note that, although fuzzy set theory can help to quantify system reliability, when data is unavailable, iteration of the analysis is recommended when such data is available. Whenever new knowledge or evidence is available to update the prior belief about the failure rate or probability a component, it should be updated to achieve a proper reflection of the real behaviour of the component. Bayesian networks are most suitable approach for such an iterative approach. In the recent years, the popularity of BNs have increased rapidly in the system safety and reliability analysis applications due to their flexible structure and ability to reason under uncertainty. Considering the multiple advantages provided by the BNs, it is worth exploring further the use of fuzzy set theory with BNs.

Another issue worth mentioning is that even where software tool support exists, it requires a lot of manual effort to create and evaluate different safety and reliability analysis artefacts such as fault trees and FMEAs. Modelbased safety analysis (MBSA) [5, 203], which automates much of the generation and evaluation process of safety and reliability artefacts, has attracted significant interest from industry and academia. Although the issue of uncertainty in the failure data has been addressed in classical risk assessment approaches by incorporating fuzzy set theory, no effort has been made to address the same issue in the context of MBSA. Considering the advantages provided by the MBSA approaches over manual approaches, it is worthwhile exploring the use of uncertain data in the context of MBSA, thus allowing automatic safety and reliability evaluation of systems under the conditions of uncertainty. 


\section{Conclusion}

Safety-critical systems are an integral part of our life. When they fail, the human, environmental and financial costs are significant. Many risk assessment approaches such as FTA and FMEA have been widely applied to evaluate system safety and reliability prior to deployment and help increase system defences. In their classical forms, these techniques rely on precise failure data. However, such data are often unavailable or scarce, introducing uncertainty in the process. Both aleatory and epistemic uncertainties have been addressed by combining fuzzy set theory with risk assessment approaches, and in this paper, we extensively reviewed fuzzy fault tree analysis, fuzzy FMEA, fuzzy event tree analysis, fuzzy Bayesian networks, fuzzy Markov chains, and fuzzy Petri nets. These approaches enable us to draw helpful conclusions even in the absence of concrete failure data. However, there are still challenges in this area, which we have discussed in detail in section 7. Future research efforts should be directed in these areas. In particular, we would like to emphasize the need to incorporate the use of fuzzy set theory in the context of MBSA, an emerging paradigm which although provides tools and techniques to automate system safety and reliability analysis, it is unable to deal with uncertainties.

\section{Acknowledgements}

This work was funded by the DEIS H2020 project (Grant Agreement 732242).

\section{References}

[1] H. Abdo, J.-M. Flaus, Monte Carlo simulation to solve fuzzy dynamic fault tree, IFAC-PapersOnLine. 49(12) (2016) 1886-1891. doi:10.1016/j.ifacol.2016.07.905.

[2] E. Adar, M. İnce, B. Karatop, M.S. Bilgili, The risk analysis by failure mode and effect analysis (FMEA) and fuzzy-FMEA of supercritical water gasification system used in the sewage sludge treatment, J. Environ. Chem. Eng. 5(1) (2017) 1261-1268. doi:10.1016/j.jece.2017.02.006.

[3] P. Agarwal, H.S. Nayal, Possibility Theory versus Probability Theory in Fuzzy Measure Theory, J. Eng. Res. Appl. 5 (2015) 37-43.

[4] M. Ahmadi, K. Behzadian, A. Ardeshir, Z. Kapelan, Comprehensive risk management using fuzzy FMEA and MCDA techniques in highway construction projects, J. Civ. Eng. Manag. 23(2) (2017) 300310. doi:10.3846/13923730.2015.1068847.

[5] J. Aizpurua, E. Muxika, Model-Based Design of Dependable Systems : Limitations and Evolution of Analysis and Verification Approaches, Int. J. Adv. Sec. 6(1) (2013) 12-31.

[6] J.D. Andrews, S.J. Dunnett, Event-tree analysis using binary decision diagrams, IEEE Trans. Reliab. 49(2) (2000) 230-238. doi:10.1109/24.877343.

[7] F. Aqlan, E.M. Ali, Integrating lean principles and fuzzy bow-tie analysis for risk assessment in chemical industry, J. Loss Prev. Process Ind. 29 (2014) 39-48. doi:10.1016/j.jlp.2014.01.006.

[8] A. Ardeshir, M. Amiri, Y. Ghasemi, M. Errington, Risk assessment of construction projects for water conveyance tunnels using fuzzy fault tree analysis, Int. J. Civ. Eng. 12(4) (2014) 396-412.

[9] A. Arnold, G. Point, A. Griffault, A. Rauzy, The AltaRica formalism for describing concurrent systems, Fundam. Informaticae. 40 (2000) 109-124.

[10] N.W. Aung, W. Haijun, S. Di, Fuzzy Fault Tree Analysis of the Marine Diesel Engine Jacket Water Cooling System, Inf. Technol. J. 13(3) (2014) 425-433.

[11] K.E. Avrachenkov, E. Sanchez, Fuzzy markov chains: Specifities and properties, in: 8th IPMU Conf., 2000: pp. 1851-1856. 
[12] K.E. Avrachenkov, E. Sanchez, Fuzzy Markov Chains and Decision-Making, Fuzzy Optim. Decis. Mak. 1(2) (2002) 143-159. doi:10.1023/A:1015729400380.

[13] J.F. Baldwin, J. Lawry, T.P. Martin, A mass assignment theory of the probability of fuzzy events, Fuzzy Sets Syst. 83 (1996) 353-367.

[14] F.A. Batzias, C.C. Siontorou, Investigating the Causes of Biosensor SNR Decrease by Means of Fault Tree Analysis, IEEE Trans. Instrum. Meas. 54(4) (2005) 1395-1406. doi:10.1109/TIM.2005.851056.

[15] M. Ben-Daya, A. Raouf, A revised failure mode and effects analysis model, Int. J. Qual. Reliab. Manag. 13(1) (1996) 43-47. doi:10.1108/02656719610108297.

[16] P.T.T. Binh, T.Q.D. Khoa, Application of Fuzzy Markov in calculating reliability of power systems, in: Transm. Distrib. Conf. Expo., 2006: pp. 6-9. doi:10.1109/TDCLA.2006.311384.

[17] B. Bittner, M. Bozzano, R. Cavada, A. Cimatti, M. Gario, A. Griggio, C. Mattarei, A. Micheli, G. Zampedri, The xSAP safety analysis platform, in: Int. Conf. Tools Algorithms Constr. Anal. Syst., 2016: pp. 533-539.

[18] A. Bobbio, L. Portinale, M. Minichino, E. Ciancamerla, Improving the analysis of dependable systems by mapping fault trees into Bayesian networks, Reliab. Eng. Syst. Saf. 71(3) (2001) 249-260. doi:10.1016/S0951-8320(00)00077-6.

[19] A. Bobbio, G. Franceschinis, R. Gaeta, L. Portinale, Exploiting Petri Nets to Support Fault Tree Based Dependability Analysis, in: 8th Int. Work. Petri Nets Perform. Model., IEEE, Zaragoza, 1999: pp. 146155.

[20] H. Boudali, J.B. Dugan, A discrete-time Bayesian network reliability modeling and analysis framework, Reliab. Eng. Syst. Saf. 87(3) (2005) 337-349. doi:10.1016/j.ress.2004.06.004.

[21] H. Boudali, J.B. Dugan, A Continuous-Time Bayesian Network Reliability Modeling, and Analysis Framework, IEEE Trans. Reliab. 55(1) (2006) 86-97.

[22] J.B. Bowles, C.E. Pelaez, Application of fuzzy logic to reliability engineering, Proc. IEEE. 83(3) (1995) 435-449. doi:10.1109/5.364489.

[23] M. Bozzano, A. Villafiorita, The FSAP/NuSMV-SA Safety Analysis Platform, Int. J. Softw. Tools Technol. Transf. - Spec. Sect. Adv. Autom. Verif. Crit. Syst. 9 (2007) 5-24.

[24] M. Braglia, M. Frosolini, R. Montanari, Fuzzy criticality assessment model for failure modes and effects analysis, Int. J. Qual. Reliab. Manag. 20(4) (2003) 503-524.

[25] J.J. Buckley, E. Eslami, Fuzzy Markov chains: uncertain probabilities, Mathw. Soft Comput. 9(1) (2002) 1-10. https://upcommons.upc.edu/handle/2099/3616.

[26] K. Cai, System failure engineering and fuzzy methodology: an introductory overview, Fuzzy Sets Syst. 83(2) (1996) 113-133.

[27] R.S. Chanda, P.K. Bhattacharjee, A reliability approach to transmission expansion planning using fuzzy fault-tree model, Electr. Power Syst. Res. 45(2) (1998) 101-108. doi:10.1016/S0378-7796(97)01226-1.

[28] K.-H. Chang, Evaluate the orderings of risk for failure problems using a more general RPN methodology, Microelectron. Reliab. 49(12) (2009) 1586-1596. doi:10.1016/j.microrel.2009.07.057.

[29] K.-H. Chang, C.-H. Cheng, A risk assessment methodology using intuitionistic fuzzy set in FMEA, Int. J. Syst. Sci. 41(12) (2010) 1457-1471. doi:10.1080/00207720903353633.

[30] K.-H. Chang, T.-C. Wen, A novel efficient approach for DFMEA combining 2-tuple and the OWA operator, Expert Syst. Appl. 37(3) (2010) 2362-2370. doi:10.1016/j.eswa.2009.07.026.

[31] S.-Y. Chang, C.-T. Chang, A fuzzy-logic based fault diagnosis strategy for process control loops, Chem. Eng. Sci. 58(15) (2003) 3395-3411. doi:10.1016/S0009-2509(03)00218-5.

[32] Z. Chen, X. Wu, J. Qin, Risk assessment of an oxygen-enhanced combustor using a structural model based on the FMEA and fuzzy fault tree, J. Loss Prev. Process Ind. 32 (2014) 349-357. doi:10.1016/j.jlp.2014.10.004. 
[33] F. Chiacchio, M. Cacioppo, D. D’urso, G. Manno, N. Trapani, L. Compagno, A Weibull-based compositional approach for hierarchical dynamic fault trees, Reliab. Eng. Syst. Saf. 109 (2013) 45-52. doi:10.1016/j.ress.2012.07.005.

[34] K.-S. Chin, A. Chan, J.-B. Yang, Development of a fuzzy FMEA based product design system, Int. J. Adv. Manuf. Technol. 36(7-8) (2008) 633-649. doi:10.1007/s00170-006-0898-3.

[35] K.-S. Chin, Y.-M. Wang, G.K.K. Poon, J.-B. Yang, Failure mode and effects analysis using a groupbased evidential reasoning approach, Comput. Oper. Res. 36(6) (2009) 1768-1779. doi:10.1016/j.cor.2008.05.002.

[36] G. Choquet, Theory of capacities, Ann. L’institut Fourier. 5 (1954) 131-295.

[37] M.-H. Chun, K.-I. Ahn, Assessment of the potential applicability of fuzzy set theory to accident progression event trees with phenomenological uncertainties, Reliab. Eng. Syst. Saf. 37(3) (1992) 237252. doi:10.1016/0951-8320(92)90130-D.

[38] D. Codetta-Raiteri, The Conversion of Dynamic Fault Trees to Stochastic Petri Nets, as a case of Graph Transformation, Electron. Notes Theor. Comput. Sci. 127(2) (2005) 45-60.

[39] C. Dağsuyu, E. Göçmen, M. Narlı, A. Kokangül, Classical and fuzzy FMEA risk analysis in a sterilization unit, Comput. Ind. Eng. 101 (2016) 286-294. doi:10.1016/j.cie.2016.09.015.

[40] R. Degani, G. Bortolan, The problem of linguistic approximation in clinical decision making, Int. J. Approx. Reason. 2 (1988) 143-162.

[41] M. Delgado, F. Herrera, L. Herrera-Viedma, E. Martinez, Combining numerical and linguistic information in group decision making, Inf. Sci. (Ny). 107 (1998) 177-194.

[42] M. Detyniecki, Mathematical aggregation operators and their application to video querying, 2000.

[43] F. Ding, J.Q. Dang, J.C. Yin, Application of Fuzzy Fault Tree Analysis in Aero-Engine, Appl. Mech. Mater. 602-605 (2014) 857-861. doi:10.4028/www.scientific.net/AMM.602-605.857.

[44] F. Dinmohammadi, M. Shafiee, A fuzzy-FMEA risk assessment approach for offshore wind turbines, Int. J. Progn. Heal. Manag. 4(13) (2013) 59-68.

[45] O. Doguc, J.E. Ramirez-Marquez, A generic method for estimating system reliability using Bayesian networks, Reliab. Eng. Syst. Saf. 94(2) (2009) 542-550.

[46] L. Du, Q. Li, Fuzzy fault tree analysis of conventional propellant temperature control system, in: 11th Syst. Syst. Eng. Conf., IEEE, 2016: pp. 1-5. doi:10.1109/SYSOSE.2016.7542898.

[47] R. Duan, H. Zhou, Diagnosis strategy for micro-computer controlled straight electro-pneumatic braking system using fuzzy set and dynamic fault tree, Maint. Reliab. 16(2) (2014) 217-223.

[48] R. Duan, J. Fan, Reliability Evaluation of Data Communication System Based on Dynamic Fault Tree under Epistemic Uncertainty, Math. Probl. Eng. 2014 (2014) 1-9. doi:10.1155/2014/674804.

[49] D. Dubois, H. Prade, Weighted minimum and maximum operations in fuzzy set theory, Inf. Sci. (Ny). 39 (1986) 205-210.

[50] A.G. Eleye-Datubo, A. Wall, J. Wang, Marine and offshore safety assessment by incorporative risk modeling in a fuzzy-Bayesian network of an induced mass assignment paradigm, Risk Anal. 28(1) (2008) 95-112. doi:10.1111/j.1539-6924.2008.01004.x.

[51] J.D. Esary, F. Proschan, Coherent Structures of Non-Identical Components, Technometrics. 5(2) (1963) 191-209.

[52] R. Ferdous, F. Khan, B. Veitch, P.R. Amyotte, Methodology for computer aided fuzzy fault tree analysis, Process Saf. Environ. Prot. 87(4) (2009) 217-226.

[53] R. Ferdous, F. Khan, R. Sadiq, P. Amyotte, B. Veitch, Handling data uncertainties in event tree analysis, Process Saf. Environ. Prot. 87(5) (2009) 283-292. doi:10.1016/j.psep.2009.07.003.

[54] R. Ferdous, F. Khan, R. Sadiq, P. Amyotte, B. Veitch, Fault and Event Tree Analyses for Process Systems Risk Analysis: Uncertainty Handling Formulations, Risk Anal. 31(1) (2011) 86-107. 
doi:10.1111/j.1539-6924.2010.01475.x.

[55] R. Ferdous, F. Khan, R. Sadiq, P. Amyotte, B. Veitch, Analyzing system safety and risks under uncertainty using a bow-tie diagram: An innovative approach, Process Saf. Environ. Prot. 91(1-2) (2013) 1-18. doi:10.1016/j.psep.2011.08.010.

[56] R. Flage, P. Baraldi, E. Zio, T. Aven, Probability and Possibility-Based Representations of Uncertainty in Fault Tree Analysis, Risk Anal. 33(1) (2013) 121-133. doi:10.1111/j.1539-6924.2012.01873.x.

[57] Ford Motor Company, Potential failure mode and effects analysis (FMEA) reference manual, 1988.

[58] S. Frühwirth-Schnatter, On fuzzy Bayesian inference, Fuzzy Sets Syst. 60(1) (1993) 41-58. doi:10.1016/0165-0114(93)90288-S.

[59] H. Furuta, N. Shiraishi, Fuzzy importance in fault tree analysis, Fuzzy Sets Syst. 12(3) (1984) $205-213$. doi:10.1016/0165-0114(84)90068-X.

[60] M. Gao, M. Zhou, X. Huang, Z. Wu, Fuzzy reasoning Petri nets, IEEE Trans. Syst. Man Cybern.-Part A: Syst. Hum, 33 (2003), 314-324.

[61] H. Garg, Reliability analysis of repairable systems using Petri nets and Vague Lambda-Tau methodology, ISA Trans., 52 (2013), 6-18.

[62] H. Gargama, S.K. Chaturvedi, Criticality Assessment Models for Failure Mode Effects and Criticality Analysis Using Fuzzy Logic, IEEE Trans. Reliab. 60(1) (2011) 102-110. doi:10.1109/TR.2010.2103672.

[63] H. Ge, S. Asgarpoor, Reliability evaluation of equipment and substations with fuzzy markov processes, IEEE Trans. Power Syst. 25(3) (2010) 1319-1328. doi:10.1109/TPWRS.2009.2038387.

[64] R. Gholizadeh, A.M. Shirazi, B.S. Gildeh, E. Deiri, Fuzzy Bayesian system reliability assessment based on Pascal distribution, Str. Mul. Opt., 40 (2010), 467-475.

[65] M. Gierczak, The quantitative risk assessment of MINI, MIDI and MAXI Horizontal Directional Drilling Projects applying Fuzzy Fault Tree Analysis, Tunn. Undergr. Sp. Technol. 43 (2014) 67-77. doi:10.1016/j.tust.2014.04.003.

[66] M.A. Gil, M. López-Díaz, Fundamentals and Bayesian analyses of decision problems with fuzzy-valued utilities, Int. J. Approx. Reason. 15(3) (1996) 203-224. doi:10.1016/S0888-613X(96)00073-4.

[67] P. Gmytrasiewicz, J.A. Hassberger, J.C. Lee, Fault tree based diagnostics using fuzzy logic, IEEE Trans. Pattern Anal. Mach. Intell. 12(11) (1990) 1115-1119.

[68] L. Görkemli, S.K. Ulusoy, Fuzzy Bayesian reliability and availability analysis of production systems, Comput. Ind. Eng. 59 (2010) 690-696. doi:10.1016/j.cie.2010.07.020.

[69] A.C.F. Guimarees, N.F.F. Ebecken, FuzzyFTA : a fuzzy fault tree system for uncertainty analysis, Ann. Nucl. Energy. 26(6) (1999) 523-532.

[70] A.C.F. Guimarães, C.M.F. Lapa, Effects analysis fuzzy inference system in nuclear problems using approximate reasoning, Ann. Nucl. Energy. 31(1) (2004) 107-115. doi:10.1016/S0306-4549(03)001737.

[71] A.C.F. Guimarães, C.M.F. Lapa, Fuzzy FMEA applied to PWR chemical and volume control system, Prog. Nucl. Energy. 44(3) (2004) 191-213. doi:10.1016/S0149-1970(04)90010-8.

[72] A.C.F. Guimarães, C.M.F. Lapa, Hazard and operability study using approximate reasoning in lightwater reactors passive systems, Nucl. Eng. Des. 236(12) (2006) 1256-1263. doi:10.1016/j.nucengdes.2005.11.007.

[73] R. Gulati, J.B. Dugan, A Modular Approach for Analyzing Static and Dynamic Fault Trees, in: Proc. Annu. Reliab. Maintainab. Symp., 1997: pp. 57-63. doi:10.1109/RAMS.1997.571665.

[74] Y. Guo, X. Meng, D. Wang, T. Meng, S. Liu, R. He, Comprehensive risk evaluation of long-distance oil and gas transportation pipelines using a fuzzy Petri net model, J. Nat. Gas Sci. Eng. 33 (2016) 18-29. doi:10.1016/j.jngse.2016.04.052. 
[75] S. Gupta, J. Bhattacharya, Reliability Analysis of a conveyor system using hybrid data, Qual. Reliab. Eng. Int. 23(7) (2007) 867-882. doi:10.1002/qre.843.

[76] A. Hadi-Vencheh, S. Hejazi, Z. Eslaminasab, A fuzzy linear programming model for risk evaluation in failure mode and effects analysis, Neural Comput. Appl. 22(6) (2013) 1105-1113. doi:10.1007/s00521012-0874-9.

[77] G. Hao, H. Guan, D. Qiu, W. Du, Reliability Analysis of Relay Protection Based on the Fuzzy-Markov Model, Int. J. Hybrid Inf. Technol. 8(10) (2015) 115-128.

[78] S. Helvacioglu, E. Ozen, Fuzzy based failure modes and effect analysis for yacht system design, Ocean Eng. 79 (2014) 131-141. doi:10.1016/j.oceaneng.2013.12.015.

[79] E.J. Henley, H. Kumamoto, Reliability engineering and risk assessment, Prentice-Hall Englewood Cliffs (NJ), 1981 .

[80] F. Herrera, S. Alonso, F. Chiclana, E. Herrera-Viedma, Computing with words in decision making: foundations, trends and prospects, Fuzzy Optim. Decis. Mak. 8 (2009) 337-364.

[81] F. Herrera, E. Herrera-Viedma, Linguistic decision analysis: steps for solving decision problems under linguistic information, Fuzzy Sets Syst. 115 (2000) 67-82.

[82] J.L. Hou, P. Jin, G.B. Cai, Failure mode of reusable rocket engine based on fuzzy fault tree and factor analysis, J. Aerosp. Power. 29 (2014) 987-992. http://en.cnki.com.cn/Article_en/CJFDTOTALHKDI201404032.htm.

[83] H.-M. Hsu, C.-T. Chen, Aggregation of fuzzy opinions under group decision making, Fuzzy Sets Syst. 79(3) (1996) 279-285. doi:10.1109/FUZZ.2001.1007275.

[84] D. Huang, T. Chen, M.-J.J. Wang, A fuzzy set approach for event tree analysis, Fuzzy Sets Syst. 118(1) (2001) 153-165. doi:10.1016/S0165-0114(98)00288-7.

[85] H. Huang, Y. Li, J. Sun, Y. Yang, N. Xiao, Fuzzy dynamic fault tree analysis for the solar array drive assembly, J. Mech. Eng. 49(19) (2013) 70-76.

[86] H.Z. Huang, M.J. Zuo, Z.Q. Sun, Bayesian reliability analysis for fuzzy lifetime data, Fuzzy Sets Syst. 157(12) (2006) 1674-1686. doi:10.1016/j.polymdegradstab.2005.12.004.

[87] C.-Y. Huang, Y.-R. Chang, An improved decomposition scheme for assessing the reliability of embedded systems by using dynamic fault trees, Reliab. Eng. Syst. Saf. 92 (2007) 1403-1412. doi:10.1016/j.ress.2006.09.008.

[88] G.S. Hura, J.W. Atwood, The Use Of Petri Nets To Analyze Coherent Fault Trees, IEEE Trans. Reliab. 37(5) (1988) 469-474.

[89] K.S. Jeong, K.W. Lee, S.Y. Jeong, H.K. Lim, Estimation on probability of radiological hazards for nuclear facilities decommissioning based on fuzzy and event tree method, Ann. Nucl. Energy. 38(11) (2011) 2606-2611. doi:10.1016/j.anucene.2011.07.004.

[90] S. Kabir, Compositional Dependability Analysis of Dynamic Systems with Uncertainty, PhD Thesis, University of Hull, 2016.

[91] S. Kabir, An overview of Fault Tree Analysis and its application in model based dependability analysis, Expert Syst. Appl. 77 (2017) 114-135. doi:10.1016/j.eswa.2017.01.058.

[92] S. Kabir, E. Edifor, M. Walker, N. Gordon, Quantification of Temporal Fault Trees Based on Fuzzy Set Theory, in: Proc. Ninth Int. Conf. Dependability Complex Syst. DepCoS-RELCOMEX, Springer International Publishing, Brunów, 2014: pp. 255-264. doi:10.1007/978-3-319-07013-1_24

[93] S. Kabir, M. Walker, Y. Papadopoulos, Reliability analysis of dynamic systems by translating temporal fault trees into Bayesian networks, in: F. Ortmeier, A. Rauzy (Eds.), Model. Saf. Assess., Springer International Publishing, Cham, 2014: pp. 96-109. doi:10.1007/978-3-319-12214-4_8.

[94] S. Kabir, M. Walker, Y. Papadopoulos, Quantitative evaluation of Pandora Temporal Fault Trees via Petri Nets, IFAC-PapersOnLine. 48 (2015) 458-463. doi:10.1016/j.ifacol.2015.09.569. 
[95] S. Kabir, M. Walker, Y. Papadopoulos, Dynamic system safety analysis in HiP-HOPS with Petri Nets and Bayesian Networks, Saf. Sci. 105 (2018) 55-70. doi:10.1016/j.ssci.2018.02.001.

[96] S. Kabir, M. Walker, Y. Papadopoulos, E. Rüde, P. Securius, Fuzzy temporal fault tree analysis of dynamic systems, Int. J. Approx. Reason. 77 (2016) 20-37. doi:10.1016/j.ijar.2016.05.006.

[97] C. Kahraman, İ. Kaya, Ö. Şenvar, Healthcare Failure Mode and Effects Analysis Under Fuzziness, Hum. Ecol. Risk Assess. An Int. J. 19(2) (2013) 538-552. doi:10.1080/10807039.2012.737753.

[98] M. Kasaeyan, J. Wang, I. Jenkinson, L. Miri, Fuzzy consequence modelling of hydrocarbon offshore pipeline, J. Mar. Sci. Eng. 1(1) (2011) 3-12.

[99] R. Kenarangui, Event-tree analysis by fuzzy probability, IEEE Trans. Reliab. 40(1) (1991) 120-124.

[100] A. Kharola, S.B. Singh, Development of fuzzy failure mode and effect analysis (FFMEA) model for risk priority number (RPN) analysis, Adv. Model. Optim. 16(1) (2014) 211-222.

[101] C.E. Kim, Y.J. Ju, M. Gens, Multilevel Fault Tree Analysis Using Fuzzy Numbers, Comput. Oper. Res. 23(7) (1996) 695-703.

[102] K.B. Kim, H.J. Shim, M.S. Jae, Fuzzy Uncertainty Evaluation for Fault Tree Analysis, in: Proc. KNS 2015 Spring Meet., 2015.

[103] E.P. Klement, R. Mesiar, E. Pap, Triangular norms, Springer Science \& Business Media, 2013.

[104] J. Knezevic, E.R. Odoom, Reliability modelling of repairable systems using Petri nets and fuzzy Lambda-Tau methodology, Reliab. Eng. Syst. Saf. 73(1) (2001) 1-17. doi:10.1016/S09518320(01)00017-5.

[105] Komal, Fuzzy fault tree analysis for patient safety risk modeling in healthcare under uncertainty, Appl. Soft Comput. 37 (2015) 942-951.

[106] R. Kruse, R. Buck-Emden, R. Cordes, Processor power considerations — An application of fuzzy markov chains, Fuzzy Sets Syst. 21(3) (1987) 289-299. doi:10.1016/0165-0114(87)90130-8.

[107] A. Kumar, S. Lata, Reliability evaluation of condensate system using fuzzy Markov model, Ann. Fuzzy Math. Informatics. 4(2) (2012) 281-291.

[108] P. Kumar, S.B. Singh, Fuzzy Fault Tree Analysis using Level $(\lambda, \rho)$ Interval-Valued Fuzzy Numbers, Math. Theory Model. 5(2) (2015) 136-142.

[109] H. Langseth, L. Portinale, Bayesian networks in reliability, Reliab. Eng. Syst. Saf. 92(1) (2007) 92-108. doi:10.1016/j.ress.2005.11.037.

[110] S.M. Lavasani, N. Ramzali, F. Sabzalipour, E. Akyuz, Utilisation of Fuzzy Fault Tree Analysis (FFTA) for quantified risk analysis of leakage in abandoned oil and natural-gas wells, Ocean Eng. 108 (2015) 729-737. doi:10.1016/j.oceaneng.2015.09.008.

[111] S.M. Lavasani, A. Zendegani, M. Celik, An extension to Fuzzy Fault Tree Analysis (FFTA) application in petrochemical process industry, Process Saf. Environ. Prot. 93 (2015) 75-88. doi:10.1016/j.psep.2014.05.001.

[112] J. Lawry, A methodology for computing with words, Int. J. Approx. Reason. 28 (2001) 51-89.

[113] J. Lawry, A framework for linguistic modelling., Artif. Intell. 155 (2004) 1-39.

[114] J. Lawry, An alternative approach to computing with words, Int. J. Uncertainty, Fuzziness KnowledgeBased Syst. 9 (2001) 3-16.

[115] J. Lawry, Label Semantics: A formal framework for modeling with words, in: Eur. Conf. Symb. Quant. Approaches to Reason. with Uncertain., 2001: pp. 374-384.

[116] J. Lawry, An overview of computing with words using label semantics, in: Fuzzy Sets Their Extensions Represent. Aggreg. Model., 2008: pp. 65-87.

[117] J. Lawry, Y. Tang, Uncertainty modelling for vague concepts: A prototype theory approach, Artif. Intell. 173 (2009) 1539-1558. 
[118] H.S. Lee, Optimal consensus of fuzzy opinions under group decision making environment, Fuzzy Sets Syst. 132(3) (2002) 303-315. doi:10.1016/S0165-0114(02)00056-8.

[119] M.L. Leuschen, I.D. Walker, J.R. Cavallaro, Robot reliability through fuzzy Markov models, in: Annu. Reliab. Maintainab. Symp., 1998: pp. 209-214. doi:10.1109/RAMS.1998.653739.

[120] N.G. Leveson, J.L. Stolzy, Safety Analysis Using Petr Nets, IEEE Trans. Softw. Eng. 13(3) (1987) 386397.

[121] M. Lewis, J. Lawry, A label semantics approach to linguistic hedges, Int. J. Approx. Reason. 55 (2014) 1147-1163.

[122] P. Li, G. Chen, L. Dai, L. Zhang, A fuzzy Bayesian network approach to improve the quantification of organizational influences in HRA frameworks, Saf. Sci. 50(7) (2012) 1569-1583. doi:10.1016/j.ssci.2012.03.017.

[123] Z.H. Li, Q.X. Gao, J. Hui, Risk Assessment on Fuzzy Fault Tree Analysis for Power Transmission Line Field Maintenance Work, Adv. Mater. Res. 1044-1045 (2014) 412-416. doi:10.4028/www.scientific.net/AMR.1044-1045.412.

[124] Y.F. Li, H.Z. Huang, Y. Liu, N. Xiao, H. Li, A new fault tree analysis method : fuzzy dynamic fault tree analysis, Eksploat. I Niezawodn. Reliab. 14(3) (2012) 208-214.

[125] Q.P. Li, G.D. Liu, J. Zhang, Y.F. Ren, The groundwater environmental risks assessment based on fuzzy fault tree analysis method to the oil pipeline, Environ. Sci. Technol. 6 (2013) 328-333.

[126] Y.-F. Li, J. Mi, Y.U. Liu, Y.-J. Yang, H.-Z. Huang, Dynamic fault tree analysis based on continuoustime Bayesian networks under fuzzy numbers, Proc. Inst. Mech. Eng. Part O J. Risk Reliab. 229(6) (2015) 530-541. doi:10.1177/1748006X15588446.

[127] G.-S. Liang, M.-J.J. Wang, Fuzzy fault-tree analysis using failure possibility, Microelectron. Reliab. 33(4) (1993) 583-597.

[128] L.Q. Lin, S.J. Chen, Z.F. Tan, Fuzzy Fault Tree Analysis Model for Grid Operation Risk Warning Evaluation, East China Electr. Power. 42 (2014) 229-233.

[129] C. Lin, M.J. Wang, Hybrid fault tree analysis using fuzzy sets, Reliab. Eng. Syst. Saf. 58(3) (1997) 205213.

[130] H.-C. Liu, Y.-Z. Chen, J.-X. You, H. Li, Risk evaluation in failure mode and effects analysis using fuzzy digraph and matrix approach, J. Intell. Manuf. 27(4) (2016) 805-816. doi:10.1007/s10845-0140915-6.

[131] Y. Liu, E.E. Kerre, An overview of fuzzy quantifiers.(I). Interpretations, Fuzzy Sets Syst. 95 (1998) 121.

[132] Y. Liu, E.E. Kerre, An overview of fuzzy quantifiers.(II). Reasoning and applications, Fuzzy Sets Syst. 95 (1998) 135-146.

[133] H.-C. Liu, Q.-L. Lin, M.-L. Ren, Fault diagnosis and cause analysis using fuzzy evidential reasoning approach and dynamic adaptive fuzzy Petri nets, Comput. Ind. Eng. 66(4) (2013) 899-908. doi:10.1016/j.cie.2013.09.004.

[134] H.-C. Liu, L. Liu, Q.-H. Bian, Q.-L. Lin, N. Dong, P.-C. Xu, Failure mode and effects analysis using fuzzy evidential reasoning approach and grey theory, Expert Syst. Appl. 38(4) (2011) 4403-4415. doi:10.1016/j.eswa.2010.09.110.

[135] H.-C. Liu, L. Liu, P. Li, Failure mode and effects analysis using intuitionistic fuzzy hybrid weighted Euclidean distance operator, Int. J. Syst. Sci. 45(10) (2014) 2012-2030. doi:10.1080/00207721.2012.760669.

[136] H.-C. Liu, L. Liu, Q.-L. Lin, Fuzzy Failure Mode and Effects Analysis Using Fuzzy Evidential Reasoning and Belief Rule-Based Methodology, IEEE Trans. Reliab. 62(1) (2013) 23-36. doi:10.1109/TR.2013.2241251.

[137] H.C. Liu, L. Liu, N. Liu, Risk evaluation approaches in failure mode and effects analysis: A literature 
review, Expert Syst. Appl. 40(2) (2013) 828-838.

[138] H.-C. Liu, J.-X. You, X.-Y. You, M.-M. Shan, A novel approach for failure mode and effects analysis using combination weighting and fuzzy VIKOR method, Appl. Soft Comput. 28 (2015) 579-588. doi:10.1016/j.asoc.2014.11.036.

[139] C. Lu, J. Lan, Z. Wang, Aggregation of fuzzy opinions under group decision-making based on similarity and distance, J. Syst. Sci. Complex. 19(1) (2006) 63-71. doi:10.1007/s11424-006-0063-y.

[140] W. Lu, L. Wei, Fuzzy fault tree analysis on G1000 system, in: Int. Conf. Inf. Sci. Electron. Electr. Eng., IEEE, 2014: pp. 1821-1824. doi:10.1109/InfoSEEE.2014.6946236.

[141] Y.A. Mahmood, A. Ahmadi, A.K. Verma, A. Srividya, U. Kumar, Fuzzy fault tree analysis : a review of concept and application, Int. J. Syst. Assur. Eng. Manag. 4(1) (2013) 19-32. doi:10.1007/s13198-0130145-x.

[142] M. Malhotra, K.S. Trivedi, Dependability Modeling Using Petri-Nets, IEEE Trans. Reliab. 44(3) (1995) $428-440$.

[143] S. Mandal, J. Maiti, Risk analysis using FMEA: Fuzzy similarity value and possibility theory based approach, Expert Syst. Appl. 41(7) (2014) 3527-3537. doi:10.1016/j.eswa.2013.10.058.

[144] M.S. Mannan, Lees' Loss prevention in the process industries: Hazard identification, assessment and control, Butterworth-Heinemann, 2012.

[145] A.S. Markowski, M.S. Mannan, Fuzzy risk matrix, J. Hazard. Mater. 159(1) (2008) 152-157. doi:10.1016/j.jhazmat.2008.03.055.

[146] O. Martin, G.J. Klir, On the problem of retranslation in computing with perceptions, Int. J. Gen. Syst. 35 (2006) 655-674.

[147] W. Mechri, C. Simon, F. Bicking, K. Ben Othman, Fuzzy multiphase Markov chains to handle uncertainties in safety systems performance assessment, J. Loss Prev. Process Ind. 26(4) (2013) 594604. doi:10.1016/j.jlp.2012.12.002.

[148] J.M. Mendel, Computing with words and its relationships with fuzzistics, Inf. Sci. (Ny). 177 (2007) 988-1006.

[149] J.M. Mendel, The perceptual computer: An architecture for computing with words, in: 10th IEEE Int. Conf. Fuzzy Syst., 2001: pp. 35-38.

[150] J.M. Mendel, An architecture for making judgments using computing with words, Int. J. Appl. Math. Comput. Sci. 12 (2002) 325-335.

[151] A. Mhalla, S. Collart Dutilleul, E. Craye, M. Benrejeb, Estimation of failure probability of milk manufacturing unit by fuzzy fault tree analysis, J. Intell. Fuzzy Syst. 26(2) (2014) 741-750. doi:10.3233/IFS-130764.

[152] S. Mirza, M. Jafari, M. Omidvari, S.M.R.M. Lavasani, The application of fuzzy logic to determine the failure probability in fault tree risk analysis, Saf. Promot. Inj. Prev. 2(2) (2014) 113-123.

[153] K.B. Misra, K.P. Soman, Multi State Fault Tree Analysis Using Fuzzy Probability Vectors and Resolution Identity, in: Reliab. Saf. Anal. under Fuzziness, Physica-Verlag HD, Heidelberg, 1995: pp. 113-125. doi:10.1007/978-3-7908-1898-7_7.

[154] K.B. Misra, G.G. Weber, Use of fuzzy set theory for level-I studies in probabilistic risk assessment, Fuzzy Sets Syst. 37(2) (1990) 139-160. doi:10.1016/0165-0114(90)90038-8.

[155] S. Montani, L. Portinale, A. Bobbio, D. Codetta-Raiteri, Radyban: A tool for reliability analysis of dynamic fault trees through conversion into dynamic Bayesian networks, Reliab. Eng. Syst. Saf. 93(7) (2008) 922-932.

[156] P. Mou, F. Tao, C. Jia, W. Ma, A copula-based function model in fuzzy reliability analysis on the planetary steering gear, in: Int. Conf. Qual. Reliab. Risk, Maintenance, Saf. Eng., IEEE, 2013: pp. 375378. doi:10.1109/QR2MSE.2013.6625605. 
[157] M. Nadjafi, M.A. Farsi, H. Jabbari, Reliability analysis of multi-state emergency detection system using simulation approach based on fuzzy failure rate, Int. J. Syst. Assur. Eng. Manag. (2016) 1-10. doi:10.1007/s13198-016-0563-7.

[158] M. Neil, D. Marquez, Availability modelling of repairable systems using Bayesian networks, Eng. Appl. Artif. Intell. 25(4) (2012) 698-704.

[159] M. Neil, M. Tailor, D. Marquez, N. Fenton, P. Hearty, Modelling dependable systems using hybrid Bayesian networks, Reliab. Eng. Syst. Saf. 93(7) (2008) 933-939.

[160] T. Onisawa, An approach to human reliability in man-machine systems using error possibility, Fuzzy Sets Syst. 27(2) (1988) 87-103.

[161] OREDA, Offshore Reliability Data Handbook, 4. ed., Trondheim, 2002.

[162] L.B. Page, J.E. Perry, Standard deviation as an alternative to fuzziness in fault tree models, IEEE Trans. Reliab. 43(3) (1994) 402-407. doi:10.1109/24.326434.

[163] N. Pan, Evaluation of building performance using fuzzy FTA, Constr. Manag. Econ. 24(12) (2006) 1241-1252. doi:10.1080/01446190600851066.

[164] H. Pan, L. Liu, Fuzzy Bayesian networks - a general formalism for representation, inference and learning with hybrid Bayesian networks, Int. J. Pattern Recognit. Artif. Intell. 14(7) (2000) 941-962. doi:10.1016/S0218-0014(00)00060-X.

[165] N.. Pan, H. Wang, Assessing failure of bridge construction using fuzzy fault tree analysis, in: IEEE Int. Conf. Fuzzy Syst. Knowl. Discov., 2007: pp. 96-100.

[166] H. Pan, W. Yun, Fault tree analysis with fuzzy gates, Comput. Ind. Eng. 33(3) (1997) 569-572. doi:10.1016/S0360-8352(97)00195-2.

[167] D. Panchal, D. Kumar, Risk analysis of compressor house unit in thermal power plant using integrated fuzzy FMEA and GRA approach, Int. J. Ind. Syst. Eng. 25(2) (2017) 228-250. doi:10.1504/IJISE.2017.081519.

[168] Y. Papadopoulos, J. Mcdermid, R. Sasse, G. Heiner, Analysis and synthesis of the behaviour of complex programmable electronic systems in conditions of failure, J. Reliab. Eng. Syst. Saf. 71 (2001) 229-247.

[169] Y. Papadopoulos, M. Walker, D. Parker, S. Sharvia, L. Bottaci, S. Kabir, L. Azevedo, I. Sorokos, A synthesis of logic and bio-inspired techniques in the design of dependable systems, Annu. Rev. Control. 41 (2016) 170-182. doi:10.1016/j.arcontrol.2016.04.008.

[170] K. Patrai, I. Uprety, Estimating Reliability of Degradable Computing System using Fuzzy Logic, Int. J. Curr. Eng. Technol. 4(3) (2014) 1226-1230.

[171] Z. Peng, M. Xiaodong, Y. Zongrun, Y. Zhaoxiang, An Approach of Fault Diagnosis for System Based on Fuzzy Fault Tree, in: Int. Conf. Multimed. Inf. Technol., IEEE, 2008: pp. 697-700. doi:10.1109/MMIT.2008.142.

[172] A. Pillay, J. Wang, Modified failure mode and effects analysis using approximate reasoning, Reliab. Eng. Syst. Saf. 79(1) (2003) 69-85.

[173] B. Praba, R. Sujatha, V.H.C. Gnanam, Fuzzy Probist Reliability of a Communication Network Using Unified Fuzzy Markov Model, Int. J. Recent Trends Eng. 2(1) (2009) 12-16.

[174] B. Praba, R. Sujatha, S. Srikrishna, Fuzzy Reliability Measures of Fuzzy Probabilistic Semi-Markov Model, Int. J. Recent Trends Eng. Technol. 2(2) (2009) 25-30.

[175] J.H. Purba, Fuzzy probability on reliability study of nuclear power plant probabilistic safety assessment: A review, Prog. Nucl. Energy. 76 (2014) 73-80. doi:10.1016/j.pnucene.2014.05.010.

[176] J.H. Purba, A fuzzy-based reliability approach to evaluate basic events of fault tree analysis for nuclear power plant probabilistic safety assessment, Ann. Nucl. Energy. 70 (2014) 21-29. doi:10.1016/j.anucene.2014.02.022.

[177] J.H. Purba, J. Lu, G. Zhang, An Intelligent System by Fuzzy Reliability Algorithm in Fault Tree 
Analysis for Nuclear Power Plant Probabilistic Safety Assessment, Int. J. Comput. Intell. Appl. 13(3) (2014) 1450017. doi:10.1142/S1469026814500175.

[178] J.H. Purba, J. Lu, G. Zhang, W. Pedrycz, A fuzzy reliability assessment of basic events of fault trees through qualitative data processing, Fuzzy Sets Syst. 243 (2014) 50-69. doi:10.1016/j.fss.2013.06.009.

[179] J.H. Purba, D.T.S. Tjahyani, Quantification of uncertainty in fault tree analysis by fuzzy approach, J. Teknol. Reakt. Nukl. 16(1) (2014) 21-31.

[180] J.H. Purba, D.T. S. Tjahyani, A.S. Ekariansyah, H. Tjahjono, Fuzzy probability based fault tree analysis to propagate and quantify epistemic uncertainty, Ann. Nucl. Energy. 85 (2015) 1189-1199. doi:10.1016/j.anucene.2015.08.002.

[181] J.H. Purba, D.T.S. Tjahyani, S. Widodo, H. Tjahjono, $\alpha$-Cut method based importance measure for criticality analysis in fuzzy probability - Based fault tree analysis, Ann. Nucl. Energy, 110 (2017), 234243.

[182] J. Qi, X. Hu, X. Gao, Quantitative risk analysis of subsea pipeline and riser: an experts' assessment approach using fuzzy fault tree, Int. J. Reliab. Saf. 8(1) (2014) 33-50. doi:10.1504/IJRS.2014.062639.

[183] N. Rachieru, N. Belu, D.C. Anghel, Evaluating the Risk of Failure on Injection Pump Using Fuzzy FMEA Method, Appl. Mech. Mater. 657 (2014) 976-980. doi:10.4028/www.scientific.net/AMM.657.976.

[184] S. Rajakarunakaran, A.M. Kumar, V.A. Prabhu, Applications of fuzzy faulty tree analysis and expert elicitation for evaluation of risks in LPG refuelling station, J. Loss Prev. Process Ind. 33 (2015) 109123. doi:10.1016/j.jlp.2014.11.016.

[185] N. Ramzali, M.R.M. Lavasani, J. Ghodousi, Safety barriers analysis of offshore drilling system by employing Fuzzy event tree analysis, Saf. Sci. 78 (2015) 49-59.

[186] J. Ren, I. Jenkinson, J. Wang, D.L. Xu, J.B. Yang, An Offshore Risk Analysis Method Using Fuzzy Bayesian Network, J. Offshore Mech. Arct. Eng. 131(4) (2009) 1-28. doi:10.1115/1.3124123.

[187] H. Reza, M. Pimple, V. Krishna, J. Hilde, A Safety Analysis Method Using Fault Tree Analysis and Petri Nets, in: 2009 Sixth Int. Conf. Inf. Technol. New Gener., IEEE, Las Vegas, 2009: pp. 1089-1094.

[188] S.S. Rivera, J.H. Baron, Using fuzzy arithmetic in containment event trees, in: Int. Conf. Probabilistic Saf. Assess. - PSA, 1999: pp. 371-378.

[189] T.J. Ross, Properties of membership functions, fuzzification, and defuzzification, in: Fuzzy Log. with Eng. Appl., John Wiley \& Sons, Ltd, 2010: pp. 89-116. doi:10.1002/9781119994374.ch4.

[190] T.J. Ross, Development of membership functions, in: Fuzzy Log. with Eng. Appl., John Wiley \& Sons, 2004: pp. 174-210.

[191] Y. Ru, C.N. Hadjicostis, Fault diagnosis in discrete event systems modeled by petri nets with outputs, in: 9th Int. Work. Discret. Event Syst., 2008: pp. 443-448. doi:10.1109/WODES.2008.4605987.

[192] S.H. Rubin, Computing with words, IEEE Trans. Syst. Man, Cybern. Part B. 29 (1999) 518-524.

[193] Z. Ruijun, Z. Lulu, W. Nannan, W. Xiaowei, Reliability evaluation of a multi-state system based on interval-valued triangular fuzzy Bayesian networks, Int. J. Syst. Assur. Eng. Manag. 7(1) (2016) 16-24. doi:10.1007/s13198-015-0335-9.

[194] N.R. Sankar, B.S. Prabhu, Modified approach for prioritization of failures in a system failure mode and effects analysis, Int. J. Qual. Reliab. Manag. 18(3) (2001) 324-336.

[195] J.P. Sawyer, S.S. Rao, Fault tree analysis of fuzzy mechanical systems, Microelectron. Reliab. 34(4) (1994) 653-667. doi:10.1016/0026-2714(94)90030-2.

[196] B. Schweizer, A. Sklar, Statistical metric spaces, Pacific J. Math. 10 (1960) 313-334.

[197] B. Schweizer, A. Sklar, Probabilistic metric spaces, 1983.

[198] S. Sen, M.X. Min, Y.Z. She, Diagnosis of Coal Scraper Conveyor Based on Fuzzy Fault Tree, in: Seventh Int. Conf. Meas. Technol. Mechatronics Autom., IEEE, 2015: pp. 392-395. 
doi:10.1109/ICMTMA.2015.100.

[199] Y.E. Senol, Y.V. Aydogdu, B. Sahin, I. Kilic, Fault Tree Analysis of chemical cargo contamination by using fuzzy approach, Expert Syst. Appl. 42(12) (2015) 5232-5244. doi:10.1016/j.eswa.2015.02.027.

[200] Y.E. Senol, B. Sahin, A novel Real-Time Continuous Fuzzy Fault Tree Analysis (RC-FFTA) model for dynamic environment, Ocean Eng. 127 (2016) 70-81. doi:10.1016/j.oceaneng.2016.09.035.

[201] S.M. Seyed-Hosseini, N. Safaei, M.J. Asgharpour, Reprioritization of failures in a system failure mode and effects analysis by decision making trial and evaluation laboratory technique, Reliab. Eng. Syst. Saf. 91(8) (2006) 872-881. doi:10.1016/j.ress.2005.09.005.

[202] R.K. Sharma, D. Kumar, P. Kumar, Systematic failure mode effect analysis (FMEA) using fuzzy linguistic modelling, Int. J. Qual. Reliab. Manag. 22(9) (2005) 986-1004. doi:10.1108/02656710510625248.

[203] S. Sharvia, S. Kabir, M. Walker, Y. Papadopoulos, Model-based dependability analysis: State-of-the-art, challenges, and future outlook, in: Softw. Qual. Assur. Large Scale Complex Software-Intensive Syst., 2015: pp. 251-278. doi: 10.1016/B978-0-12-802301-3.00012-0.

[204] F.T. Sheldon, S. Grenier, M. Benzinger, Specification, Safety and Reliability Analysis Using Stochastic Petri Net Models, in: Proc. 10th Int. Work. Softw. Specif. Des., IEEE Computer Society Press, 2000: pp. 123-132.

[205] L. Shi, J. Shuai, K. Xu, Fuzzy fault tree assessment based on improved AHP for fire and explosion accidents for steel oil storage tanks, J. Hazard. Mater. 278 (2014) 529-538. doi:10.1016/j.jhazmat.2014.06.034.

[206] M.-H. Shu, C.-H. Cheng, J.-R. Chang, Using intuitionistic fuzzy sets for fault-tree analysis on printed circuit board assembly, Microelectron. Reliab. 46(12) (2006) 2139-2148. doi:10.1016/j.microrel.2006.01.007.

[207] W. Silvert, Symmetric summation : a class of operations on fuzzy sets, IEEE Trans. Syst. Man Cybern. 9 (1979) 659-667.

[208] C. Simon, P. Weber, Evidential networks for reliability analysis and performance evaluation of systems with imprecise knowledge, IEEE Trans. Rel., 58 (2009), 69-87.

[209] D. Singer, A fuzzy set approach to fault tree and reliability analysis, Fuzzy Sets Syst. 34(2) (1990) 145155.

[210] D.H. Stamatis, Failure Mode and Effect Analysis: FMEA from Theory to Execution, ASQ Quality Press, 2003.

[211] M. Sugeno, Theory of fuzzy integrals and its application, 1974.

[212] J. Sun, S.Y. Qin, Y.H. Song, Fault diagnosis of electric power systems based on fuzzy Petri nets, IEEE Trans. Pow. Sys., 19 (2004), 2053-2059.

[213] P.V. Suresh, A.K. Babar, V.V. Raj, Uncertainty in fault tree analysis : A fuzzy approach, Fuzzy Sets Syst. 83(2) (1996) 135-141.

[214] S.M. Taheri, J. Behboodian, A Bayesian approach to fuzzy hypotheses testing, Fuzzy Sets Syst. 123(1) (2001) 39-48. doi:10.1016/S0165-0114(00)00134-2.

[215] S.M. Taheri, R. Zarei, Bayesian system reliability assessment under the vague environment, App. Sof. Com., 11 (2011), 1614-1622.

[216] H. Tanaka, L.T. Fan, F.S. Lai, K. Toguchi, Fault-Tree Analysis by Fuzzy Probability, IEEE Trans. Reliab. 32(5) (1983) 453-457.

[217] Y. Tang, J. Lawry, Linguistic modelling and information coarsening based on prototype theory and label semantics, Int. J. Approx. Reason. 50 (2009) 1177-1198.

[218] M. Tanrioven, Q.H. Wu, D.R. Turner, C. Kocatepe, J. Wang, A new approach to real-time reliability analysis of transmission system using fuzzy Markov model, Electr. Power Energy Syst. 26(10) (2004) 
821-832. doi:10.1016/j.ijepes.2004.07.004.

[219] H.S. Tooranloo, A. sadat Ayatollah, A model for failure mode and effects analysis based on intuitionistic fuzzy approach, Appl. Soft Comput. 49 (2016) 238-247. doi:10.1016/j.asoc.2016.07.047.

[220] J.G. Torres-Toledan, L.E. Sucar, Bayesian networks for reliability analysis of complex systems, in: Prog. Artif. Intell. 98, 1998: pp. 195-206.

[221] E. Trillas, On the use of words and fuzzy sets, Inf. Sci. (Ny). 176 (2006) 1463-1487.

[222] P. Troger, F. Becker, F. Salfner, FuzzTrees - Failure Analysis with Uncertainties, in: IEEE 19th Pacific Rim Int. Symp. Dependable Comput., IEEE, 2013: pp. 263-272. doi:10.1109/PRDC.2013.48.

[223] T. Tsabadze, A method for fuzzy aggregation based on group expert evaluations, Fuzzy Sets Syst. 157(10) (2006) 1346-1361. doi:10.1016/j.fss.2005.11.015.

[224] J. Tu, R. Cheng, Q. Tao, Reliability Analysis Method of safety-critical avionics system based on Dynamic Fault Tree under Fuzzy Uncertainty, Maint. Reliab. 17(1) (2015) 156-163.

[225] I.B. Türkşen, Type 2 representation and reasoning for CWW, Fuzzy Sets Syst. 127 (2002) 17-36.

[226] I.B. Türkşen, Meta-linguistic axioms as a foundation for computing with words, Inf. Sci. (Ny). 177 (2007) 332-359.

[227] S.K. Tyagi, D. Pandey, V. Kumar, Fuzzy Fault Tree Analysis for Fault Diagnosis of Cannula Fault in Power Transformer, Appl. Math. 2(11) (2011) 1346-1355.

[228] L. V. Utkin, S. V. Gurov, A general formal approach for fuzzy reliability analysis in the possibility context, Fuzzy Sets Syst. 83(2) (1996) 203-213. doi:10.1016/0165-0114(95)00391-6.

[229] B. Vahdani, M. Salimi, M. Charkhchian, A new FMEA method by integrating fuzzy belief structure and TOPSIS to improve risk evaluation process, Int. J. Adv. Manuf. Technol. 77(1-4) (2015) 357-368. doi:10.1007/s00170-014-6466-3.

[230] J. Vaníček, I. Vrana, S. Aly, Fuzzy aggregation and averaging for group decision making: A generalization and survey, Knowledge-Based Syst. 22(1) (2009) 79-84. doi:10.1016/j.knosys.2008.07.002.

[231] M. Verma, A. Kumar, Y. Singh, T. Allahviranloo, Application of non-normal p-norm trapezoidal fuzzy number in reliability evaluation of electrical substations, Neural Comput. Appl. 23(2) (2013) 531-539. doi:10.1007/s00521-012-0949-7.

[232] A.K. Verma, A. Srividya, S. Prabhudeva, G. Vinod, Reliability analysis of Dynamic fault tree models using fuzzy sets, Commun. Dependability Qual. Manag. 9(4) (2006) 68-78.

[233] W.E. Vesely, M. Stamatelatos, J. Dugan, J. Fragola, J. Minarick, J. Railsback, Fault tree handbook with aerospace applications, NASA office of safety and mission assurance, Wasshington DC, (2002).

[234] R. Viertl, On reliability estimation based on fuzzy lifetime data, J. Stat. Plan. Inf., 139 (2009), 17501755 .

[235] H.E. Virtanen, A Study in Fuzzy Petri Nets and the Relationship to Fuzzy Logic Programming, Åbo, 1995. http://citeseerx.ist.psu.edu/viewdoc/download?doi=10.1.1.30.7790\&rep=rep1\&type=pdf.

[236] Y. Vishwakarma, S.P. Sharma, Uncertainty analysis of an industrial system using Intuitionistic Fuzzy Set Theory, Int. J. Syst. Assur. Eng. Manag. 7 (2016) 73-83. doi:10.1007/s13198-015-0384-0.

[237] L.X. Wang, A course in fuzzy system and control, Prentice-Hall PTR, 1997.

[238] H.L. Wang, Reliability evaluation of household appliance protection system based on fuzzy fault tree analysis, in: 12th Int. Conf. Fuzzy Syst. Knowl. Discov., IEEE, 2015: pp. 564-569. doi:10.1109/FSKD.2015.7382004.

[239] Y.-M. Wang, K.-S. Chin, G.K.K. Poon, J.-B. Yang, Risk evaluation in failure mode and effects analysis using fuzzy weighted geometric mean, Expert Syst. Appl. 36(2) (2009) 1195-1207. doi:10.1016/j.eswa.2007.11.028. 
[240] H. Wang, X. Lu, Y. Du, C. Zhang, R. Sadiq, Y. Deng, Fault tree analysis based on TOPSIS and triangular fuzzy number, Int. J. Syst. Assur. Eng. Manag. (2014) 1-7. doi:10.1007/s13198-014-0323-5.

[241] J. Wang, R. Nie, H. Zhang, X. Chen, New operators on triangular intuitionistic fuzzy numbers and their applications in system fault analysis, Inf. Sci. (Ny). 251 (2013) 79-95. doi:10.1016/j.ins.2013.06.033.

[242] D. Wang, P. Zhang, L. Chen, Fuzzy fault tree analysis for fire and explosion of crude oil tanks, J. Loss Prev. Process Ind. 26(6) (2013) 1390-1398. doi:10.1016/j.jlp.2013.08.022.

[243] D. Wang, Y. Zhang, X. Jia, P. Jiang, B. Guo, Handling Uncertainties in Fault Tree Analysis by a Hybrid Probabilistic-Possibilistic Framework, Qual. Reliab. Eng. Int. 32 (2015) 1137-1148. doi:10.1002/qre.1821.

[244] N.A. Wessiani, S.O. Sarwoko, Risk Analysis of Poultry Feed Production Using Fuzzy FMEA, Procedia Manuf. 4 (2015) 270-281. doi:10.1016/j.promfg.2015.11.041.

[245] H.C. Wu, Bayesian system reliability assessment under fuzzy environments, Reliab. Eng. Syst. Saf. 83(3) (2004) 277-286. doi:10.1016/j.ress.2003.09.021.

[246] H.C. Wu, Fuzzy Bayesian system reliability assessment based on exponential distribution, Appl. Math. Model. 30(6) (2006) 509-530. doi:10.1016/j.apm.2005.05.014.

[247] J. Wu, S. Yan, L. Xie, Reliability analysis method of a solar array by using fault tree analysis and fuzzy reasoning Petri net, Acta Astronaut. 69(11-12) (2011) 960-968. doi:10.1016/j.actaastro.2011.07.012.

[248] J. Wu, S. Yan, L. Xie, P. Gao, Reliability apportionment approach for spacecraft solar array using fuzzy reasoning Petri net and fuzzy comprehensive evaluation, Acta Astronaut. 76 (2012) 136-144. doi:10.1016/j.actaastro.2012.02.023.

[249] C. Xia, Analysis and application of the worming cable robot fuzzy fault tree, J. Mach. Des. 8 (2015).

[250] K. Xu, H.M. Li, S.S. Lu, Safety Risk Analysis of Box-Culvert Jacking Construction by Using Fuzzy Fault Tree Method Based on WBS-RBS, Adv. Mater. Res. 838-841 (2013) 355-359. doi:10.4028/www.scientific.net/AMR.838-841.355.

[251] R.R. Yager, On the retranslation process in Zadeh's paradigm of computing with words, IEEE Trans. Syst. Man, Cybern. Part B. 34 (2004) 1184-1195.

[252] R.R. Yager, A new methodology for ordinal multiobjective decisions based on fuzzy sets, Decis. Sci. 12 (1981) 589-600.

[253] R.R. Yager, On ordered weighted averaging aggregation operators in multi-criteria decision making, IEEE Trans. Syst. Man Cybern. 18 (1988) 183-190.

[254] F. Yan, K. Xu, X. Yao, Y. Li, Fuzzy Bayesian Network-Bow-Tie Analysis of Gas Leakage during Biomass Gasification, PLoS One. 11(7) (2016) 1-21. doi:10.1371/journal.pone.0160045.

[255] W. Yanfu, X. Min, Approach to integrate fuzzy fault tree with Bayesian network, Procedia Eng. 45 (2012) 131-138. doi:10.1016/j.proeng.2012.08.133.

[256] L.P. Yang, Analysis on Dynamic Fault Tree Based on Fuzzy Set, Appl. Mech. Mater. 110 (2011) 24162420.

[257] Z. Yang, S. Bonsall, J. Wang, Fuzzy rule-based Bayesian reasoning approach for prioritization of failures in FMEA, IEEE Trans. Reliab. 57(3) (2008) 517-528.

[258] M. Yazdi, Hybrid Probabilistic Risk Assessment Using Fuzzy FTA and Fuzzy AHP in a Process Industry, J. Fail. Anal. Prev. 17 (2017) 756-764. doi:10.1007/s11668-017-0305-4.

[259] M. Yazdi, S. Daneshvar, H. Setareh, An extension to Fuzzy Developed Failure Mode and Effects Analysis ( FDFMEA ) application for aircraft landing system, Saf. Sci. 98 (2017) 113-123.

[260] M. Yazdi, S. Kabir, A Fuzzy Bayesian Network approach for Risk Analysis in Process Industries, Process Saf. Environ. Prot. (2017). doi:10.1016/j.psep.2017.08.015.

[261] M. Yazdi, F. Nikfar, M. Nasrabadi, Failure probability analysis by employing fuzzy fault tree analysis, Int. J. Syst. Assur. Eng. Manag. (2017) 1-17. doi:10.1007/s13198-017-0583-y. 
[262] M. Yazdi, E. Zarei, Uncertainty Handling in the Safety Risk Analysis: An Integrated Approach Based on Fuzzy Fault Tree Analysis, J. Fail. Anal. Prev. 18 (2018) 392-404. doi:10.1007/s11668-018-0421-9.

[263] T.-M. Yeh, L.-Y. Chen, Fuzzy-based risk priority number in FMEA for semiconductor wafer processes, Int. J. Prod. Res. 52(2) (2014) 539-549. doi:10.1080/00207543.2013.837984.

[264] O. Yevkin, An improved modular approach for dynamic fault tree analysis, in: Proc. Annu. Reliab. Maintainab. Symp., 2011: pp. 1-5. doi:10.1109/RAMS.2011.5754437.

[265] M. Ying, A formal model of computing with words, IEEE Trans. Fuzzy Syst. 10 (2002) 640-652.

[266] T.W. Yiu, S.O. Cheung, C.L. Lok, A Fuzzy Fault Tree Framework of Construction Dispute Negotiation Failure, IEEE Trans. Eng. Manag. 62(2) (2015) 171-183. doi:10.1109/TEM.2015.2407369.

[267] D. Yuhua, Y. Datao, Estimation of failure probability of oil and gas transmission pipelines by fuzzy fault tree analysis, J. Loss Prev. Process Ind. 18(2) (2005) 83-88.

[268] C. Yuyan, L. Ting, W. Jian, X. Rong, W. Xinmin, Fuzzy dynamic fault tree analysis for electromechanical actuator based on algebraic model with common-cause failures, Autom. Control Comput. Sci. 50(2) (2016) 80-90. doi:10.3103/S0146411616020024.

[269] L. A. Zadeh, Fuzzy Sets, Inf. Control. 8(3) (1965) 338-353.

[270] L.A. Zadeh, The concept of a linguistic variable and its application to approximate reasoning-I, Inf. Sci. (Ny). 8(3) (1975) 199-249. doi:10.1016/0020-0255(75)90036-5.

[271] L.A. Zadeh, The concept of a linguistic variable and its application to approximate reasoning-II, Inf. Sci. (Ny). 8(4) (1975) 301-357. doi:10.1016/0020-0255(75)90046-8.

[272] L.A. Zadeh, The concept of a linguistic variable and its application to approximate reasoning-III, Inf. Sci. (Ny). 9(1) (1975) 43-80. doi:10.1016/0020-0255(75)90017-1.

[273] L. A. Zadeh, Fuzzy sets as a basis for a theory of possibility, Fuzzy Sets Syst. 1(1) (1978) 3-28. doi:10.1016/0165-0114(78)90029-5.

[274] L. A. Zadeh, Probability measures of Fuzzy events, J. Math. Anal. Appl. 23(2) (1968) 421-427. doi:10.1016/0022-247X(68)90078-4.

[275] L.A. Zadeh, Outline of a new approach to the analysis of complex systems and decision processes, IEEE Trans. Syst. Man. Cybern. 1 (1973) 28-44.

[276] L.A. Zadeh, Toward a theory of fuzzy information granulation and its centrality in human reasoning and fuzzy logic, Fuzzy Sets Syst. 90 (1997) 111-127.

[277] L.A. Zadeh, Fuzzy logic= computing with words, IEEE Trans. Fuzzy Syst. 4 (1996) 103-111.

[278] L.A. Zadeh, A computational approach to fuzzy quantifiers in natural languages, Comput. Math. with Appl. 9 (1983) 149-184.

[279] M.B. Zaman, E. Kobayashi, N. Wakabayashi, S. Khanfir, T. Pitana, A. Maimun, Fuzzy FMEA model for risk evaluation of ship collisions in the Malacca Strait: based on AIS data, J. Simul. 8(1) (2014) 91104. doi:10.1057/jos.2013.9.

[280] Z. Zhang, X. Chu, Risk prioritization in failure mode and effects analysis under uncertainty, Expert Syst. Appl. 38(1) (2011) 206-214. doi:10.1016/j.eswa.2010.06.046.

[281] K. Zhang, J. Guo, F. Yuan, A Novel Transformer Fault Diagnosis Model Based on Integration of Fault Tree and Fuzzy Set, in: 11th Int. Conf. Semant. Knowl. Grids, IEEE, 2015: pp. 112-118. doi:10.1109/SKG.2015.27.

[282] L. Zhang, M.J. Skibniewski, X. Wu, Y. Chen, Q. Deng, A probabilistic approach for safety risk analysis in metro construction, Saf. Sci. 63 (2014) 8-17. doi:10.1016/j.ssci.2013.10.016.

[283] L.L. Zhang, R.J. Zhang, X.X. Si, Importance Analysis Method of Fuzzy Fault Tree Based on T-S Modle and Application in Hydraulic System, Appl. Mech. Mater. 470 (2013) 707-711. doi:10.4028/www.scientific.net/AMM.470.707. 
[284] Y. Zhang, Y. Zhang, F. Wen, C.Y. Chung, C.-L. Tseng, X. Zhang, F. Zeng, Y. Yuan, A fuzzy Petri net based approach for fault diagnosis in power systems considering temporal constraints, Int. J. Electr. Power Energy Syst. 78 (2016) 215-224. doi:10.1016/j.ijepes.2015.11.095.

[285] X. Zheng, G. Zhou, J. Dai, H. Ren, D. Li, Drive system reliability analysis of wind turbine based on fuzzy fault tree, in: 35th Chinese Control Conf., IEEE, 2016: pp. 6761-6765. doi:10.1109/ChiCC.2016.7554422.

[286] Q. Zhou, V. V. Thai, Fuzzy and grey theories in failure mode and effect analysis for tanker equipment failure prediction, Saf. Sci. 83 (2016) 74-79. doi:10.1016/j.ssci.2015.11.013.

[287] K.-Q. Zhou, A.M. Zain, Fuzzy Petri nets and industrial applications: a review, Artif. Intell. Rev. 45 (2016) 405-446. doi:10.1007/s10462-015-9451-9.

[288] L. Zhu, Z. Zhang, Y. Qin, X. Cheng, L. Kou, M. Yuan, G. Liu, Reliability Analysis of Metro Vehicles Bogie System Based on Fuzzy Fault Tree, in: Proc. 2015 Int. Conf. Electr. Inf. Technol. Rail Transp., Springer, Berlin, Heidelberg, 2016: pp. 71-81. doi:10.1007/978-3-662-49370-0_8.

[289] H. Zimmermann, Fuzzy set theory—and its applications, Springer Science \& Business Media, 2011.

[290] S.A. Zonouz, R. Berthier, P. Haghani, A Fuzzy Markov Model for scalable reliability analysis of Advanced Metering Infrastructure, in: Innov. Smart Grid Technol., 2012: pp. 1-5. doi:10.1109/ISGT.2012.6175770.

[291] S.A. Zonouz, S.G. Miremadi, A fuzzy-monte carlo simulation approach for fault tree analysis, in: Annu. Reliab. Maintainab. Symp., IEEE, 2006: pp. 428-433. doi:10.1109/RAMS.2006.1677412. 